\title{
SIFTING THROUGH THE WRECKAGE: LESSONS FROM RECENT HEDGE-FUND LIQUIDATIONS*
}

\author{
Mila Getmansky ${ }^{\mathrm{a}}$, Andrew W. Lo ${ }^{\mathrm{b}, \dagger}$ and Shauna X. Mei
}

We document the empirical properties of a sample of 1,765 funds in the TASS Hedge Fund database from 1977 to 2004 that are no longer active. The TASS sample shows that attrition rates differ significantly across investment styles, from a low of $5.2 \%$ per year on average for convertible arbitrage funds to a high of $14.4 \%$ per year on average for managed futures funds. We relate a number of factors to these attrition rates, including past performance, volatility, and investment style, and also document differences in illiquidity risk between active and liquidated funds. We conclude with a proposal for the US Securities and Exchange Commission to play a new role in promoting greater transparency and stability in the hedge-fund industry.

\section{Introduction}

*The views and opinions expressed in this article are those of the authors only, and do not necessarily represent the views and opinions of AlphaSimplex Group, MIT, the University of Massachusetts, or any of their affiliates and employees. The authors make no representations or warranty, either expressed or implied, as to the accuracy or completeness of the information contained in this article, nor are they recommending that this article serve as the basis for any investment decision — this article is for information purposes only.

${ }^{a}$ Isenberg School of Management, University of Massachusetts, Amherst, MA 01003 USA.

${ }^{b}$ MIT Sloan School of Management, and AlphaSimplex Group.

${ }^{\dagger}$ Corresponding author. MIT Sloan School of Management, 50 Memorial Drive, E52-432, Cambridge, MA 02142-1347, USA. Tel.: (617) 253-0920; e-mail: alo@mit.edu

${ }^{\mathrm{c}}$ MIT Sloan School of Management, Cambridge, MA 02142, USA.

Enticed by the prospect of double-digit returns, seemingly uncorrelated risks, and impressive trading talent, individual and institutional investors have flocked to hedge funds in recent years. In response, many sell-side traders, investment bankers, and portfolio managers have also answered the siren call of hedge funds, making this one of the fastest growing sectors in the financial services industry. Currently estimated at just over $\$ 1$ trillion in assets and about 8,000 funds, the hedge-fund industry is poised for even more growth as pension funds continue to increase their allocations to alternative investments in the wake of lackluster returns from traditional asset classes. In a December 2003 survey of 137 US defined-benefit pension plan sponsors conducted by State Street Global Advisors 
and InvestorForce, $67 \%$ of the respondents indicated their intention to increase their allocations to hedge funds, and $15 \%$ expected their increases to be "substantial."

Although these are exciting times for the hedgefund industry, there is a growing concern that both investors and managers have been too focused on the success stories of the day, forgetting about the many hedge funds that liquidate after just one or two years because of poor performance, insufficient capital to support their operations, credit issues, or conflicts between business partners. Of course, as with many other rapidly growing industries, waves of startups are followed by shake-outs, eventually leading to a more mature and stable group of survivors in the aftermath. Accordingly, it has been estimated that a fifth of all hedge funds failed last year, ${ }^{1}$ and this year the failure rate for European hedge funds has increased from $7 \%$ to $10 \%$ per annum. ${ }^{2}$

In this article, we attempt to provide some balance to the optimistic perspective of most hedge-fund industry participants by focusing our attention on hedge funds that have liquidated. By studying funds that are no longer in business, we hope to develop a more complete understanding of the risks of the industry. Although the effects of "survivorship bias" on the statistical properties of investment returns are well known, there are also qualitative perceptual biases that are harder to quantify, and such biases can be reduced by including liquidated funds in our purview.

Throughout this paper, we use the less pejorative term "liquidated fund" in place of the more common "hedge-fund failure" to refer to hedge funds that have shut down. The latter term implies a value judgment that we are in no position to make, and while there are certainly several highly publicized cases of hedge funds failing due to fraud and other criminal acts, there are many other cases of conscientious and talented managers who closed their funds after many successful years for business or personal reasons. We do not wish to confuse the former with the latter, but hope to learn from the experiences of both.

In Section 2 we provide a brief review of the hedge-fund literature, and in Section 3 we summarize the basic properties of the TASS database of live and liquidated hedge funds from 1977 to 2004. We consider the time-series and crosssectional properties of hedge-fund attrition rates in Section 4, and document the relation between attrition and performance characteristics such as volatility and lagged returns. Across style categories, higher volatility is clearly associated with higher attrition rates, and over time, lagged performance of a particular style category is inversely related to attrition in that category. In Section 5 we compare valuation and illiquidity risk across categories and between live and liquidated funds using serial correlation as a proxy for illiquidity exposure. We find that, on average, live funds seem to be engaged in less liquid investments, and discuss several possible explanations for this unexpected pattern. We conclude in Section 6 with a proposal for the US Securities and Exchange Commission to play a new role in promoting greater transparency and stability in the hedge-fund industry.

\section{Literature review}

Hedge-fund data has only recently become publicly available, hence much of the hedge-fund literature is relatively new. Thanks to data vendors such as Altvest, Hedge Fund Research (HFR), Managed Account Reports (MAR/CISDM), and TASS, researchers now have access to historical monthly returns, fund size, investment style, and many other data items for a broad collection of hedge 
funds. However, inclusion in these databases is purely voluntary and therefore somewhat idiosyncratic; hence, there is a certain degree of selection bias in the funds that agree to be listed, and the most popular databases seem to have relatively few funds in common. ${ }^{3}$ Moreover, because hedge funds are not allowed to solicit the general public, the funds' prospectuses are not included in these databases, depriving researchers of more detailed information concerning the funds' investment processes, securities traded, allowable amounts of leverage, and specific contractual terms such as high-water marks, hurdle rates, and clawback agreements. ${ }^{4}$ There is even less information about liquidated funds, apart from coarse categorizations such as those provided by TASS (see Section 3 below). In fact, most databases contain only funds that are currently active and open to new investors, and several data vendors like TASS do not provide the identities of the funds in academic versions of their databases, ${ }^{5}$ so it is difficult to track the demise of any fund through other sources.

Despite these challenges, the hedge-fund literature has blossomed into several distinct branches: performance analysis, the impact of survivorship bias, hedge-fund attrition rates, and case studies of operational risks and hedge-fund liquidations.

The empirical properties of hedge-fund performance have been documented by Ackermann, McEnally, and Ravenscraft (1999), Agarwal and Naik (2000b,c), Edwards and Caglayan (2001), Fung and Hsieh (1999, 2000, 2001), Kao (2002), and Liang (1999, 2000, 2001, 2003) using several of the databases cited above. More detailed performance attribution and style analysis for hedge funds has been considered by Agarwal and Naik (2000b,c), Brown and Goetzmann (2003), Brown et al. (1999, 2000, 2001a,b), Fung and Hsieh (1997a,b, 2002a,b), and Lochoff (2002). Asness, Krail, and Liew (2001) have questioned the neutrality of certain market-neutral hedge funds, arguing that lagged market betas indicate less hedging than expected. Lo (2001) and Getmansky, Lo, and Makarov (2004) provide an explanation for this striking empirical phenomenon-smoothed returns, which is a symptom of illiquidity in a fund's investments - and propose an econometric model to estimate the degree of smoothing and correct for its effects on performance statistics such as return volatilities, market betas, and Sharpe ratios.

The fact that hedge funds are not required to include their returns in any publicly available database induces a potentially significant selection bias in any sample of hedge funds that do choose to publicize their returns. In addition, many hedge-fund databases include data only for funds that are currently in existence, inducing a "survivorship bias" that affects the estimated mean and volatility of returns as Ackermann, McEnally and Ravenscraft (1999) and Brown et al. (1992) have documented. For example, the estimated impact of survivorship on average returns varies from a bias of $0.16 \%$ (Ackermann, McEnally, and Ravenscraft, 1999) to 2\% (Liang, 2000; Amin and Kat, 2003b) to 3\% (Brown, Goetzmann, and Ibbotson, 1999). ${ }^{6}$

The survival rates of hedge funds have been estimated by Brown, Goetzmann, and Ibbotson (1999), Fung and Hsieh (2000), Liang (2000, 2001), Brown, Goetzmann, and Park (2001a,b), Gregoriou (2002), Amin and Kat (2003b), and Bares, Gibson, and Gyger (2003). Brown, Goetzmann, and Park (2001b) show that the probability of liquidation increases with increasing risk, and that funds with negative returns for two consecutive years have a higher risk of shutting down. Liang (2000) finds that the annual hedge-fund attrition rate is $8.3 \%$ for the 1994-1998 sample period using TASS data, and Baquero, Horst, and Verbeek (2002) find a slightly higher rate of $8.6 \%$ for the 1994-2000 sample period. Baquero, Horst, and Verbeek (2002) also find that surviving funds outperform non-surviving funds by approximately 
$2.1 \%$ per year, which is similar to the findings of Fung and Hsieh (2000, 2002b) and Liang (2000), and that investment style, size, and past performance are significant factors in explaining survival rates. Many of these patterns are also documented by Liang (2000) and Boyson (2002). In analyzing the life cycle of hedge funds, Getmansky (2004) finds that the liquidation probabilities of individual hedge funds depend on fund-specific characteristics such as past returns, asset flows, age, and assets under management, as well as category-specific variables such as competition and favorable positioning within the industry.

Brown, Goetzmann, and Park (2001b) find that the half-life of the TASS hedge funds is exactly 30 months, while Brooks and Kat (2002) estimate that approximately $30 \%$ of new hedge funds do not make it past 36 months due to poor performance, and in Amin and Kat's (2003b) study, 40\% of their hedge funds do not make it to the fifth year. Howell (2001) observes that the probability of hedge funds failing in their first year was $7.4 \%$, only to increase to $20.3 \%$ in their second year. Poorperforming younger funds drop out of databases at a faster rate than older funds (see Getmansky, 2004; Jen, Heasman, and Boyatt, 2001), presumably because younger funds are more likely to take additional risks to obtain good performance which they can use to attract new investors, whereas older funds that have survived already have track records with which to attract and retain capital.

A number of case studies of hedge-fund liquidations have been published recently, no doubt spurred by the most well-known liquidation in the hedge-fund industry to date: Long-Term Capital Management (LTCM). The literature on LTCM is vast, spanning a number of books, journal articles, and news stories; a representative sample includes Greenspan (1998), McDonough (1998), Pérold (1999), the President's Working Group on Financial Markets (1999), and MacKenzie (2003). Ineichen
(2001) has compiled a list of selected hedge funds and analyzed the reasons for their liquidations. Kramer (2001) focuses on fraud, providing detailed accounts of six of history's most egregious cases. Although it is virtually impossible to obtain hard data on the frequency of fraud among liquidated hedge funds, ${ }^{7}$ in a study of over 100 liquidated hedge funds during the past two decades, Feffer and Kundro (2003) conclude that "half of all failures could be attributed to operational risk alone," of which fraud is one example. In fact, they observe that "The most common operational issues related to hedge fund losses have been misrepresentation of fund investments, misappropriation of investor funds, unauthorized trading, and inadequate resources" (Feffer and Kundro, 2003, p. 5). The last of these issues is, of course, not related to fraud, but Feffer and Kundro (2003, Figure 2) report that only $6 \%$ of their sample involved inadequate resources, whereas $41 \%$ involved misrepresentation of investments, 30\% misappropriation of funds, and 14\% unauthorized trading. These results suggest that operational issues are indeed an important factor in hedge-fund liquidations, and deserve considerable attention by investors and managers alike.

Finally, Chan et al. (2004) investigate the relation between hedge funds and "systemic" risk, usually defined as a series of correlated defaults among financial institutions that occur over a short period of time, often caused by a single major event like the default of Russian government debt in August 1998. Although systemic risk has traditionally been more of a concern for the banking sector, the events surrounding LTCM in 1998 clearly demonstrated the relevance of hedge funds for such risk exposures. Chan et al. (2004) attempt to quantify the potential impact of hedge funds on systemic risk by developing a number of new risk measures for hedge funds and applying them to individual and aggregate hedge-fund returns data. Their preliminary findings suggest that the hedge-fund industry may be heading into a challenging period of lower 
expected returns, and that systemic risk is currently on the rise.

\section{The TASS Live and Graveyard databases}

The TASS database of hedge funds consists of both active and defunct hedge funds, with monthly returns, assets under management and other fundspecific information for 4,781 individual funds from February 1977 to August $2004 .^{8}$ The database is divided into two parts: "Live" and "Graveyard" funds. Hedge funds that are in the Live database are considered to be active as of the most recent update of the database, in our case August 31, 2004. Once a hedge fund decides not to report its performance, is liquidated, closed to new investment, restructured, or merged with other hedge funds, the fund is transferred into the Graveyard database. A hedge fund can only be listed in the Graveyard database after having been listed first in the Live database. Because TASS includes both live and dead funds, the effects of suvivorship bias are reduced. However, the database is still subject to backfill bias - when a fund decides to be included in the database, TASS adds the fund to the Live database, including the fund's entire prior performance record. Hedge funds do not need to meet any specific requirements to be included in the TASS database, and reporting is purely voluntary. Due to reporting delays and time lags in contacting hedge funds, some Graveyard funds can be incorrectly listed in the Live database for a short period of time.?

As of August 31, 2004, the combined database of both live and dead hedge funds contained 4781 funds with at least one monthly return observation. Out of these 4,781 funds, 2,920 funds are in the Live database and 1,861 funds are in the Graveyard database. The earliest data available for a fund in either database is February 1977. TASS created the Graveyard database in 1994, hence it is only since 1994 that TASS began transferring funds from the
Live to the Graveyard database. Funds that were dropped from the Live database prior to 1994 are not included in the Graveyard, which may yield a certain degree of survivorship bias. ${ }^{10}$

The majority of the 4,781 funds reported returns net of management and incentive fees on a monthly basis, ${ }^{11}$ and we eliminated 50 funds that reported only gross returns, leaving 2,893 funds in the Live and 1838 funds in the Graveyard database. We also eliminated funds that reported returns on a quarterly_not monthly-basis, as well as funds that did not report assets under management, or reported only partial assets under management. These filters yielded a final sample of 4,536 hedge funds in the "Combined" database, consisting of 2,771 funds in the Live database and 1,765 funds in the Graveyard database. For the empirical analysis in Section 5, we impose an additional filter in which we require funds to have at least five years of non-missing returns, yielding 1,226 funds in the Live database and 611 in the Graveyard database for a combined total of 1,837 funds. This obviously creates additional survivorship bias in the remaining sample of funds, but since the main objective in Section 5 is to estimate measures of valuation and illiquidity risk and not to make inferences about overall performance, this filter may not be as problematic. ${ }^{12}$

TASS also classifies funds into one of 11 different investment styles, listed in Table 1 and described in the appendix. Table 1 also reports the number of funds in each category for the Live, Graveyard, and Combined databases, and it is apparent from these figures that the representation of investment styles is not evenly distributed, but is concentrated among four categories: Long/Short Equity $(1,415)$, Fund of Funds (952), Managed Futures (511), and Event Driven (384). Together, these four categories account for $71.9 \%$ of the funds in the Combined database. Figure 1 shows that the relative proportions of the Live and Graveyard databases are 
Table 1 Number of funds in the TASS Live, Graveyard, and Combined hedge-fund databases, grouped by category.

\begin{tabular}{clrrr}
\hline & & \multicolumn{3}{c}{ Number of TASS Funds in } \\
\cline { 3 - 5 } Category & \multicolumn{1}{c}{ Definition } & Live & Graveyard & Combined \\
\hline 1 & Convertible Arbitrage & 127 & 49 & 176 \\
2 & Dedicated Shortseller & 14 & 15 & 29 \\
3 & Emerging Markets & 130 & 133 & 263 \\
4 & Equity Market Neutral & 173 & 87 & 260 \\
5 & Event Driven & 250 & 134 & 384 \\
6 & Fixed-Income Arbitrage & 104 & 71 & 175 \\
7 & Global Macro & 118 & 114 & 232 \\
8 & Long/Short Equity & 883 & 532 & 1,415 \\
9 & Managed Futures & 195 & 316 & 511 \\
10 & Multi-Strategy & 98 & 41 & 139 \\
11 & Fund of Funds & 679 & 273 & 952 \\
& Total & 2,771 & 1,765 & 4,536 \\
\hline
\end{tabular}

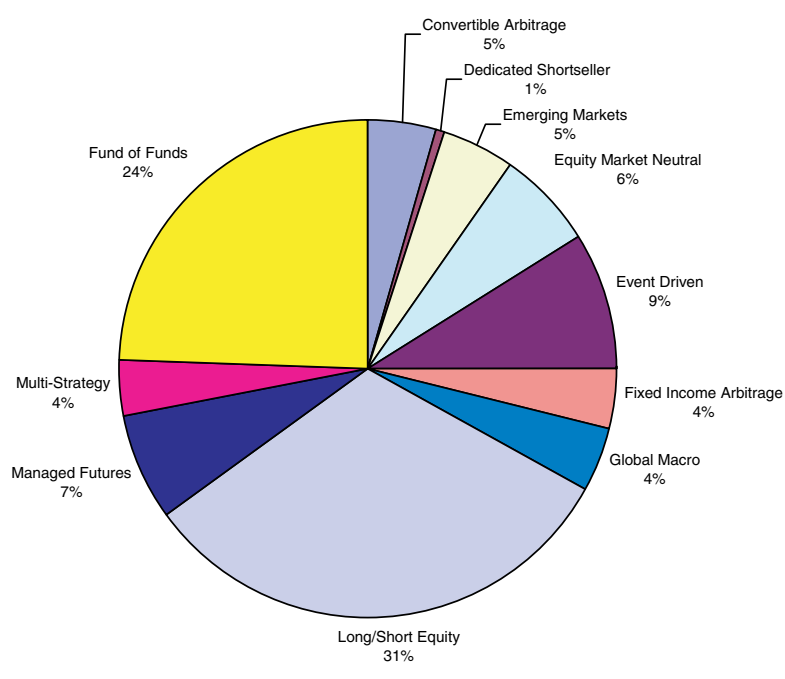

(a) Live funds

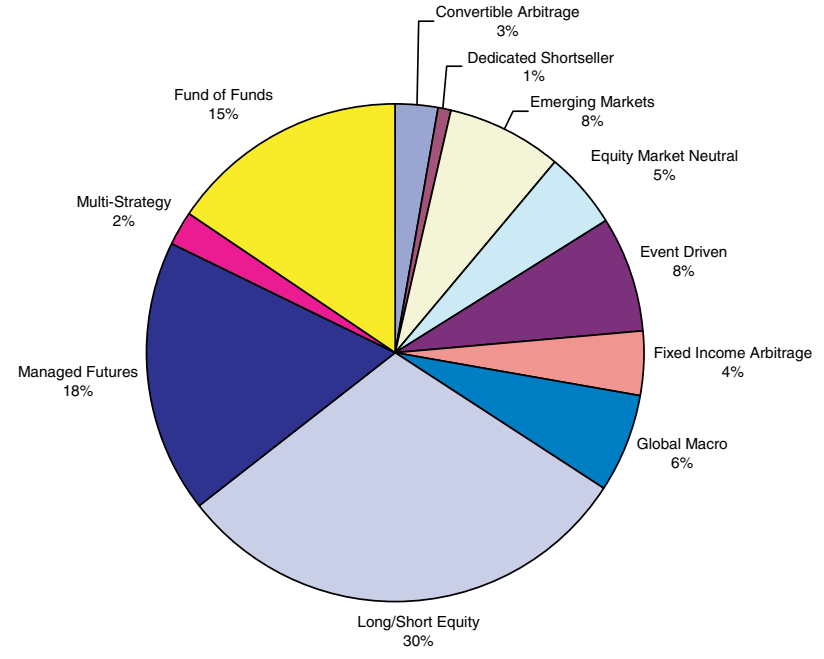

(b) Graveyard funds

Figure 1 Breakdown of TASS Live and Graveyard funds by category.

roughly comparable, with the exception of two categories: Funds of Funds (24\% in the Live and $15 \%$ in the Graveyard database), and Managed Futures (7\% in the Live and $18 \%$ in the Graveyard database). This reflects the current trend in the industry toward Funds of Funds, and the somewhat slower growth of Managed Futures funds.
Given our interest in hedge-fund liquidations, the Graveyard database will be our main focus. Because of the voluntary nature of inclusion in the TASS database, Graveyard funds do not consist solely of liquidations. TASS gives one of seven distinct reasons for each fund that is assigned to the Graveyard, summarized in Table 2. It may seem reasonable to 
Table 2 TASS status codes for funds in the Graveyard database.

\begin{tabular}{cl}
\hline Status code & \multicolumn{1}{c}{ Definition } \\
\hline 1 & Fund liquidated \\
2 & Fund no longer reporting to TASS \\
3 & TASS has been unable to contact the \\
& manager for updated information \\
4 & Fund closed to new investment \\
5 & Fund has merged into another entity \\
7 & Fund dormant \\
9 & Unknown \\
\hline
\end{tabular}

confine our attention to those Graveyard funds categorized as "liquidated" (status code 1) or perhaps to drop those funds that are closed to new investment (status code 4) from our sample. However, because our purpose is to develop a broader perspective on the dynamics of the hedge-fund industry, we argue that using the entire Graveyard database may be more informative. For example, by eliminating Graveyard funds that are closed to new investors, we create a downward bias in the performance statistics of the remaining funds. Because we do not have detailed information about each of these funds, we cannot easily determine how any particular selection criterion will affect the statistical properties of the remainder. Therefore, we choose to include the entire set of Graveyard funds in our analysis, but caution readers to keep in mind the composition of this sample when interpreting our empirical results.

For concreteness, Table 3 reports frequency counts for Graveyard funds in each status code and style category, as well as assets under management at the time of transfer to the Graveyard. ${ }^{13}$ These counts show that 1,571 of the 1,765 Graveyard funds, or $89 \%$, fall into the first three categories, categories that can plausibly be considered liquidations, and within each of these three categories, the relative frequencies across style categories are roughly comparable, with Long/Short Equity being the most numerous and Dedicated Shortseller being the least numerous. Of the remaining 194 funds with status codes 4-9, only status code 4-funds that are closed to new investors-is distinctly different in character from the other status codes. There are only seven funds in this category, and these funds are all likely to be "success stories," providing some counterbalance to the many liquidations in the Graveyard sample. Of course, this is not to say that 7 out of 1,765 is a reasonable estimate of the success rate in the hedge-fund industry, because we have not included any of the Live funds in this calculation. Nevertheless, these seven funds in the Graveyard sample do underscore the fact that hedge-fund data are subject to a variety of biases that do not always point in the same direction, and we prefer to leave them in so as to reflect these biases as they occur naturally rather than to create new biases of our own. For the remainder of this article, we shall refer to all funds in the TASS Graveyard database as "liquidations" for expositional simplicity.

Table 4 contains basic summary statistics for the funds in the TASS Live, Graveyard, and Combined databases, and Figure 2 provides a comparison of average means, standard deviations, Sharpe ratios, and first-order autocorrelation coefficients $\rho_{1}$ in the Live and Graveyard databases. ${ }^{14}$ Not surprisingly, there is a great deal of variation in mean returns and volatilities both across and within categories and databases. For example, the 127 Convertible Arbitrage funds in the Live database have an average mean return of $9.92 \%$ and an average standard deviation of $5.51 \%$, but in the Graveyard database, the 49 Convertible Arbitrage funds have an average mean return of $10.02 \%$ and a much higher average standard deviation of $8.14 \%$. As expected, average volatilities in the Graveyard database are uniformly higher than those in the Live database because the higher-volatility funds are more likely to be eliminated. This effect operates at both ends of the return distribution-funds that are wildly successful are also more likely to leave the database since they have less motivation to advertise their 
Table 3 Frequency counts and assets under management of funds in the TASS Graveyard database by category and Graveyard inclusion code. Assets under management are at the time of transfer into the Graveyard database.

\begin{tabular}{|c|c|c|c|c|c|c|c|c|c|c|c|c|}
\hline Code & $\begin{array}{l}\text { All } \\
\text { Funds }\end{array}$ & $\begin{array}{c}\text { Convert } \\
\text { Arb }\end{array}$ & $\begin{array}{l}\text { Ded } \\
\text { Short }\end{array}$ & $\begin{array}{l}\text { Emrg } \\
\text { Mkts }\end{array}$ & $\begin{array}{l}\text { EqMkt } \\
\text { Neutral }\end{array}$ & $\begin{array}{l}\text { Event } \\
\text { Driven }\end{array}$ & $\begin{array}{c}\text { Fixed } \\
\text { Income } \\
\text { Arb }\end{array}$ & $\begin{array}{l}\text { Global } \\
\text { Macro }\end{array}$ & $\begin{array}{l}\text { L/S } \\
\text { Equity }\end{array}$ & $\begin{array}{l}\text { Mged } \\
\text { Futures }\end{array}$ & $\begin{array}{l}\text { Mult- } \\
\text { Strat }\end{array}$ & $\begin{array}{l}\text { Fund of } \\
\text { Funds }\end{array}$ \\
\hline \multicolumn{13}{|c|}{ Frequency count } \\
\hline 1 & 913 & 19 & 7 & 78 & 65 & 50 & 29 & 53 & 257 & 190 & 30 & 135 \\
\hline 2 & 511 & 21 & 4 & 34 & 12 & 56 & 26 & 29 & 187 & 43 & 7 & 92 \\
\hline 3 & 147 & 4 & 1 & 7 & 8 & 17 & 3 & 17 & 54 & 18 & 1 & 17 \\
\hline 4 & 7 & 0 & 0 & 0 & 0 & 1 & 2 & 0 & 3 & 0 & 0 & 1 \\
\hline 5 & 56 & 2 & 1 & 5 & 0 & 6 & 3 & 6 & 16 & 9 & 1 & 7 \\
\hline 7 & 2 & 0 & 0 & 0 & 0 & 1 & 0 & 0 & 1 & 0 & 0 & 0 \\
\hline 9 & 129 & 3 & 2 & 9 & 2 & 3 & 8 & 9 & 14 & 56 & 2 & 21 \\
\hline Total & 1,765 & 49 & 15 & 133 & 87 & 134 & 71 & 114 & 532 & 316 & 41 & 273 \\
\hline \multicolumn{13}{|c|}{ Assets under management } \\
\hline 1 & 18,754 & 1,168 & 62 & 1,677 & 1,656 & 2,047 & 1,712 & 2,615 & 4,468 & 975 & 641 & 1,732 \\
\hline 2 & 36,366 & 6,420 & 300 & 848 & 992 & 7,132 & 2,245 & 678 & 10,164 & 537 & 882 & 6,167 \\
\hline 3 & 4,127 & 45 & 34 & 729 & 133 & 1,398 & 50 & 115 & 931 & 269 & 2 & 423 \\
\hline 4 & 487 & 0 & 0 & 0 & 0 & 100 & 31 & 0 & 250 & 0 & 0 & 106 \\
\hline 5 & 3,135 & 12 & 31 & 143 & 0 & 222 & 419 & 1,775 & 473 & 33 & 3 & 24 \\
\hline 7 & 8 & 0 & 0 & 0 & 0 & 6 & 0 & 0 & 2 & 0 & 0 & 0 \\
\hline 9 & 3,052 & 42 & 18 & 222 & 9 & 159 & 152 & 32 & 193 & 1,671 & 18 & 538 \\
\hline Total & 65,931 & 7,686 & 445 & 3,620 & 2,789 & 11,063 & 4,610 & 5,215 & 16,482 & 3,484 & 1,546 & 8,991 \\
\hline
\end{tabular}

performance. That the Graveyard database also contains successful funds is supported by the fact that in some categories, the average mean return in the Graveyard database is the same as or higher than in the Live database, e.g., Convertible Arbitrage, Equity Market Neutral, and Dedicated Shortseller.

Figure 3 displays the histogram of year-to-date returns at the time of liquidation. The fact that the distribution is skewed to the left is consistent with the conventional wisdom that performance is a major factor in determining the fate of a hedge fund. However, note that there is nontrivial weight in the right half of the distribution, suggesting that recent performance is not the only relevant factor.

Serial correlation of monthly returns - the correlation between one month's return and a previous month's return-has been proposed as a measure of smoothed returns and illiquidity exposure by Lo $(2001,2002)$ and Getmansky, Lo, and Makarov (2004), and there is considerable variation in the first-order serial correlation coefficient across the categories in the Combined database. The six categories with the highest averages are Convertible Arbitrage (31.4\%), Fund of Funds (19.6\%), Event Driven (18.4\%), Emerging Markets (16.5\%), Fixed-Income Arbitrage (16.2\%), and Multi-Strategy (14.7\%). Given the descriptions of these categories provided by TASS (see the appendix) and the fact that they involve some of the most illiquid securities traded, positive serial correlation does seem to be a reasonable proxy for valuation and illiquidity risk (see Section 5 for a more detailed analysis). In contrast, equities and futures are among the most liquid securities in 


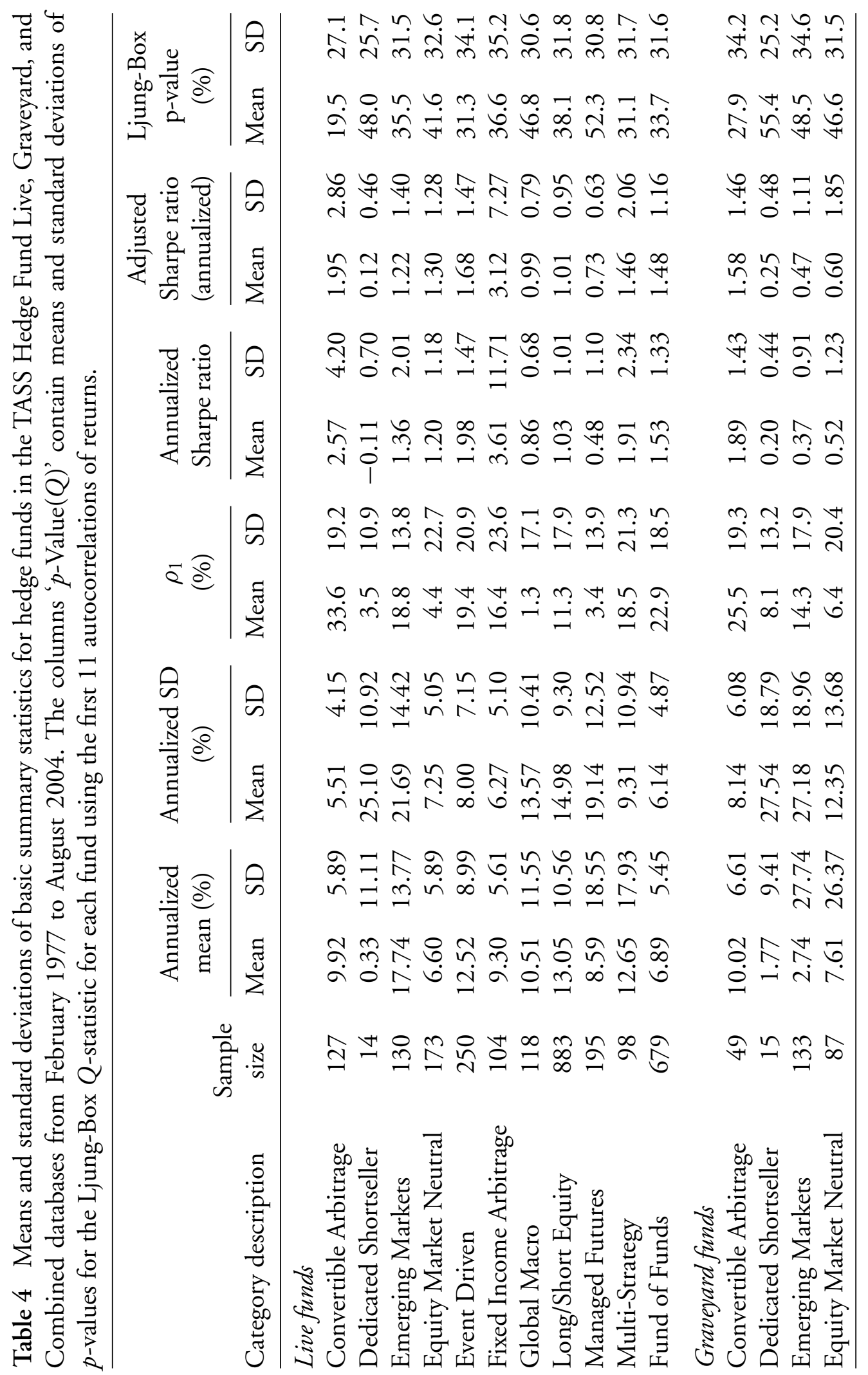




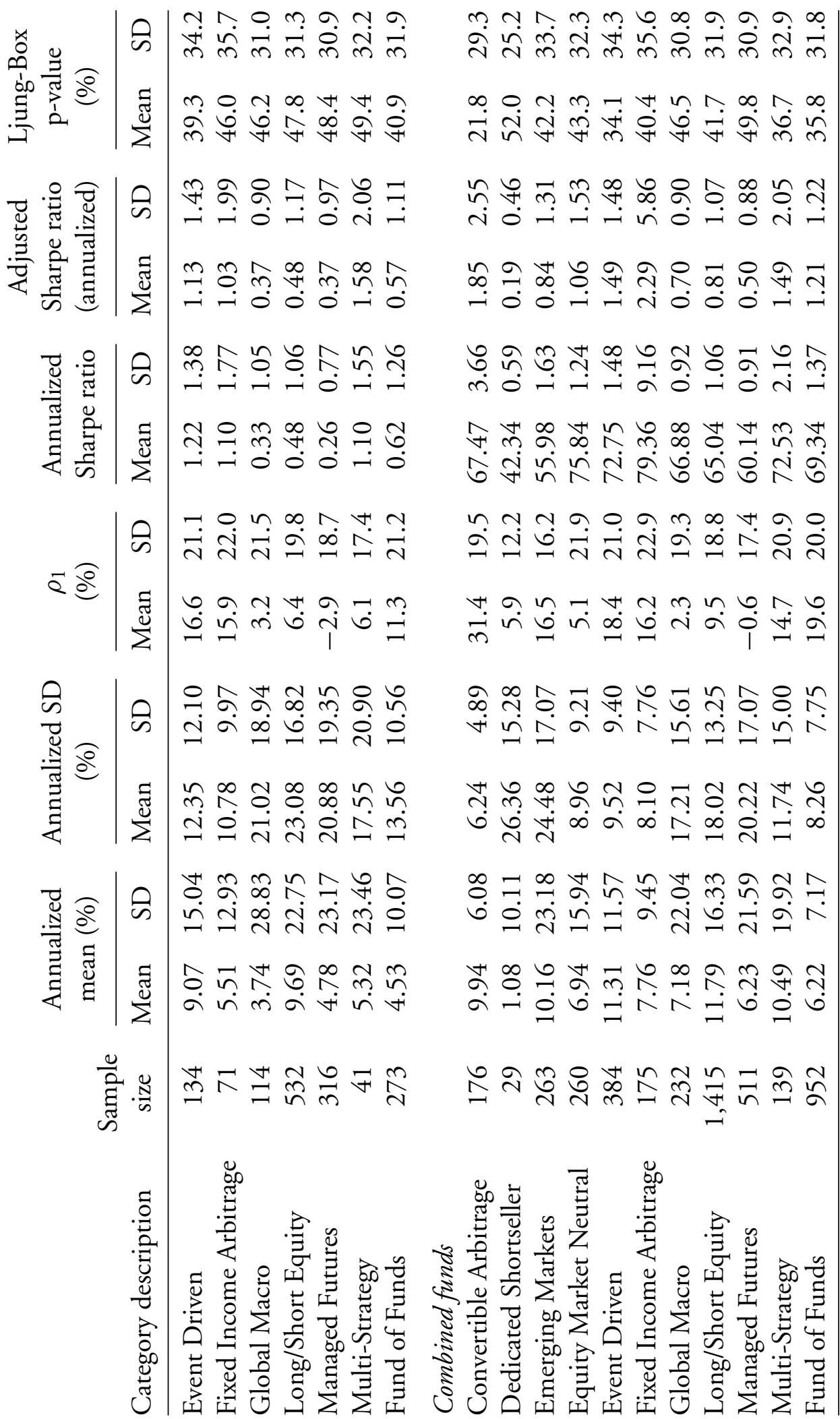




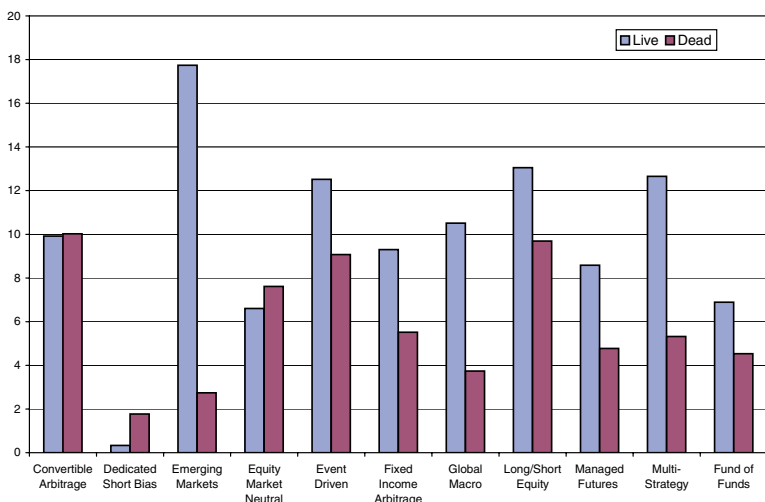

(a) Average mean return

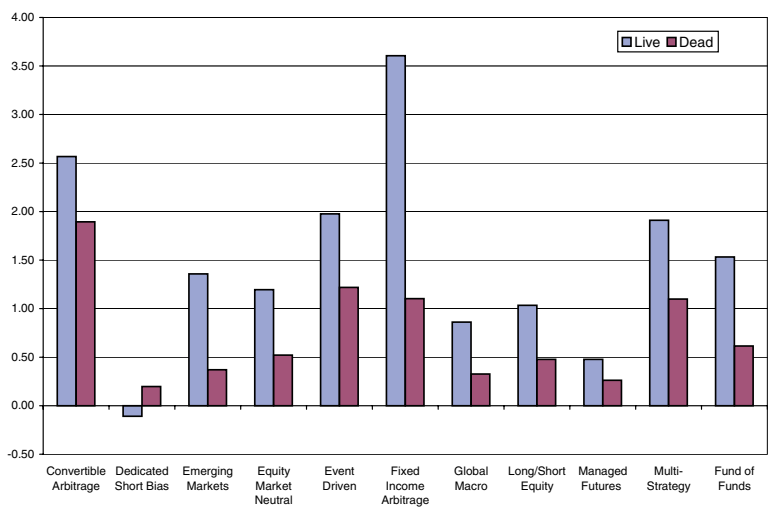

(c) Average Sharpe ratio

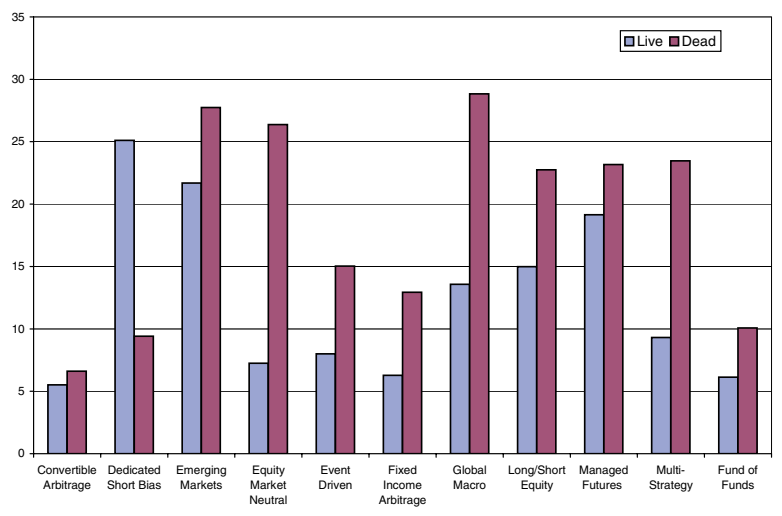

(b) Average standard deviation

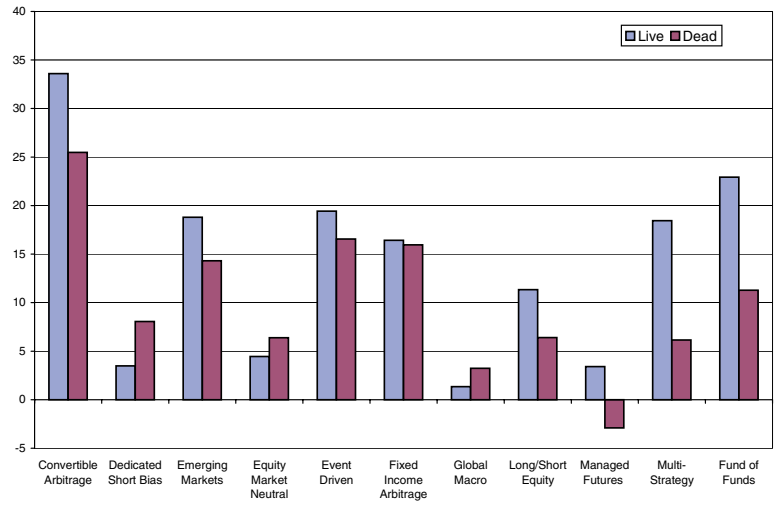

(d) Average autocorrelation

Figure 2 Comparison of average means, standard deviations, Sharpe ratios, and first-order autocorrelation coefficients for categories of funds in the TASS Live and Graveyard databases from January 1994 to August 2004.

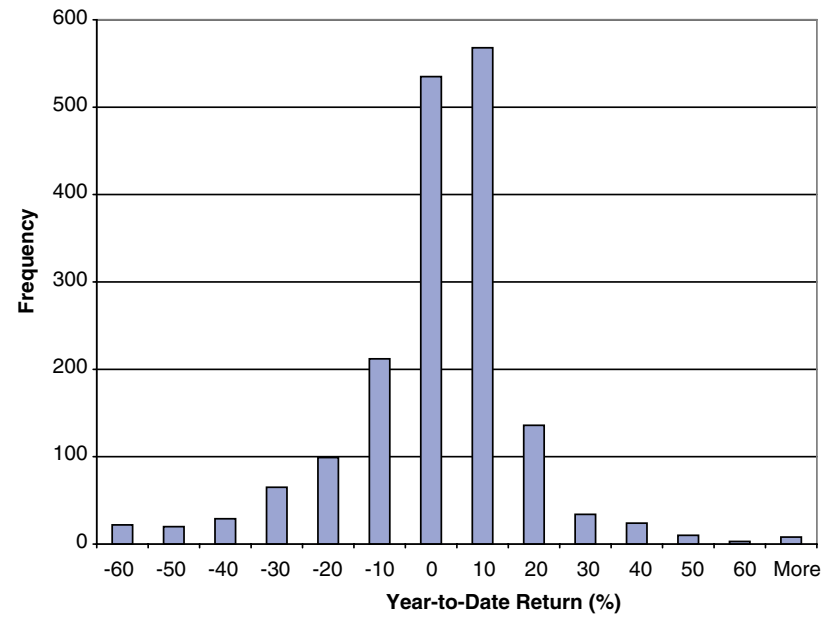

Figure 3 Histogram of year-to-date return at the time of liquidation of hedge funds in the TASS Graveyard database, January 1994 to August 2004. which hedge funds invest, and not surprisingly, the average first-order serial correlations for Equity Market Neutral, Long/Short Equity, and Managed Futures categories are $5.1 \%, 9.5 \%$, and $-0.6 \%$, respectively. Dedicated Shortseller funds also have a low average first-order autocorrelation, 5.9\%, which is consistent with the high degree of liquidity that often characterizes shortsellers (by definition, the ability to short a security implies a certain degree of liquidity). We shall return to illiquidity risk in Section 5, where we consider some surprising differences in serial correlation between Live and Graveyard funds.

Finally, Figure 4 provides a summary of two key characteristics of the Graveyard funds: the age 
distribution of funds at the time of liquidation, and the distribution of their assets under management. The median age of Graveyard funds is $\mathbf{4 5}$ months, hence half of all liquidated funds never reached their fourth anniversary. The mode of the distribution is 36 months. The median assets under management for funds in the Graveyard database is $\$ 6.3$ million, not an uncommon size for the typical startup hedge fund.

In the next two sections, we shall turn to more specific aspects of liquidated funds: attrition rates in Section 4 and valuation and illiquidity risk in Section 5.

\section{Attrition rates}

To develop a sense for the dynamics of the TASS database and the birth and death rates of hedge funds over the past decade, ${ }^{15}$ in Table 5 we report annual frequency counts of the funds in the database at the start of each year, funds entering the Live database during the year, funds exiting during the year and moving to the Graveyard database, and funds entering and exiting within the year. The panel labelled "All Funds" contains frequency counts for all funds, and the remaining 11 panels contain the same statistics for each category. Also included in Table 5 are attrition rates, defined as the ratio of funds exiting in a given year to the number of existing funds at the start of the year, and the performance of the category as measured by the annual compound return of the CSFB/Tremont Index for that category.

For the unfiltered sample of all funds in the TASS database, and over the sample period from 1994 to 2003 , the average attrition rate is $8.8 \% .{ }^{16}$ This is similar to the $8.5 \%$ attrition rate obtained by Liang (2001) for the 1994-1999 sample period. The aggregate attrition rate rises in 1998, partly due to LTCM's demise and the dislocation caused by its aftermath. The attrition rate increases to a peak of $11.4 \%$ in 2001, mostly due to the Long/Short Equity category-presumably the result of the bursting of the technology bubble.

Although $8.8 \%$ is the average attrition rate for the entire TASS database, there is considerable variation in average attrition rates across categories. Averaging the annual attrition rates from 1994 to 2003 within each category yields the following:

\begin{tabular}{lrlr}
\hline Convertible Arbitrage & $5.2 \%$ & Global Macro & $12.6 \%$ \\
Dedicated Shortseller & $8.0 \%$ & Long/Short Equity & $7.6 \%$ \\
Emerging Markets & $9.2 \%$ & Managed Futures & $14.4 \%$ \\
Equity Market Neutral & $8.0 \%$ & Multi-Strategy & $8.2 \%$ \\
Event Driven & $5.4 \%$ & Fund of Funds & $6.9 \%$ \\
Fixed Income Arbitrage & $10.6 \%$ & & \\
\hline
\end{tabular}

These averages illustrate the different risks involved in each of the 11 investment styles. At 5.2\%, Convertible Arbitrage enjoys the lowest average attrition rate, which is not surprising since this category has the second-lowest average return volatility of $5.89 \%$ (see Table 4). The highest average attrition rate is $14.4 \%$ for Managed Futures, which is also consistent with the $18.55 \%$ average volatility of this category, the highest among all 11 categories.

Within each category, the year-to-year attrition rates exhibit different patterns, partly attributable to the relative performance of the categories. For example, Emerging Markets experienced a 16.1\% attrition rate in 1998, no doubt because of the turmoil in emerging markets in 1997 and 1998, which is reflected in the $-37.7 \%$ return in the CSFB/Tremont Index Emerging Markets Index for 1998. The opposite pattern is also present-during periods of unusually good performance, attrition rates decline, as in the case of Long/Short Equity from 1995 to 2000 where attrition rates were $3.2 \%$, 


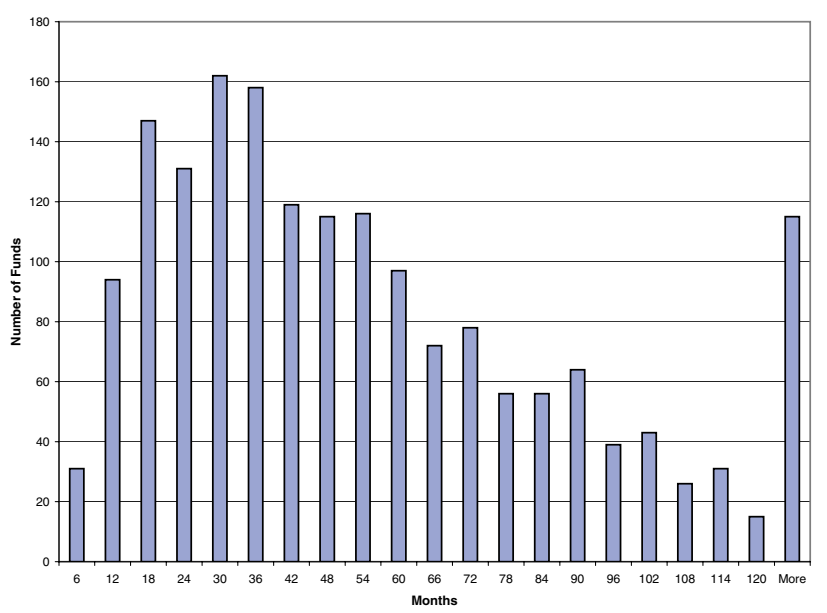

(a) Age distribution

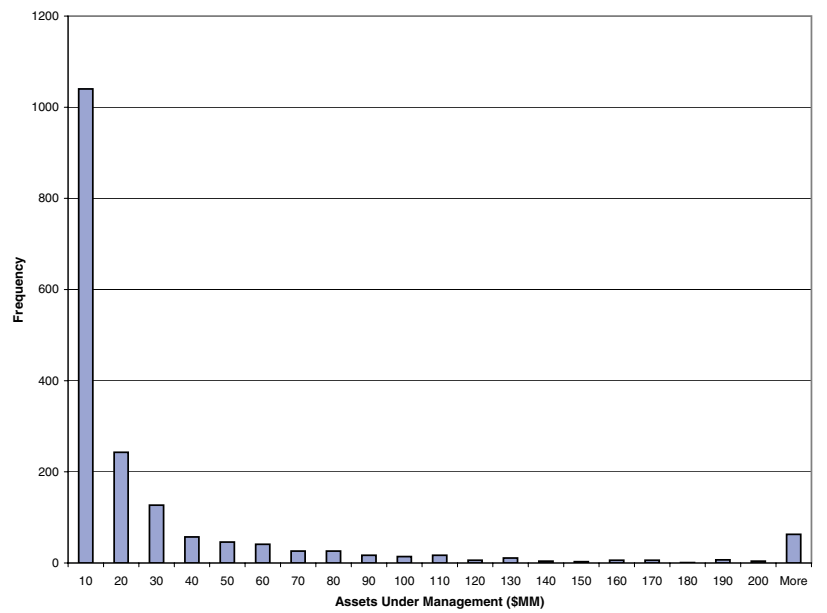

(b) Assets under management

Figure 4 Histograms of age distribution and assets under management at the time of liquidation for funds in the TASS Graveyard database, January 1994 to August 2004.

$7.4 \%, 3.9 \%, 6.8 \%, 7.4 \%$, and $8.0 \%$, respectively. Of course, in the three years following the bursting of the technology bubble-2001-2003the attrition rates for Long/Short Equity shot up to $13.4 \%, 12.4 \%$, and $12.3 \%$, respectively. These patterns are consistent with the basic economics of the hedge-fund industry: good performance begets more assets under management, greater business leverage, and staying power; poor performance leads to the Graveyard.

To develop a better sense of the relative magnitudes of attrition across categories, Table 6 and Figure 5(a) provide a decomposition by category where the attrition rates in each category are renormalized so that when they are summed across categories in a given year, the result equals the aggregate attrition rate for that year. From these renormalized figures, it is apparent that there is an increase in the proportion of the total attrition rate due to Long/Short Equity funds beginning in 2001. In fact, Table 6 shows that of the total attrition rates of $11.4 \%, 10.0 \%$, and $10.7 \%$ in the years 2001-2003, the Long/Short Equity category was responsible for 4.8, 4.3, and
4.1 percentage points of those totals, respectively. Despite the fact that the average attrition rate for the Long/Short Equity category is only $7.6 \%$ from 1994 to 2003, the funds in this category are more numerous, hence they contribute more to the aggregate attrition rate. Figure 5(b) provides a measure of the impact of these attrition rates on the industry by plotting the total assets under management of funds in the TASS database along with the relative proportions in each category. Long/Short Equity funds are indeed a significant fraction of the industry, hence the increase in their attrition rates in recent years may be a cause for some concern.

\section{Valuation and illiquidity risk}

One of the most pressing issues facing the hedgefund industry is the valuation of funds, particularly those containing assets that do not always have readily available market prices with which to mark portfolios to market. Feffer and Kundro (2003) conclude that one of the most common manifestations of fraud-which accounts for over $50 \%$ of the 


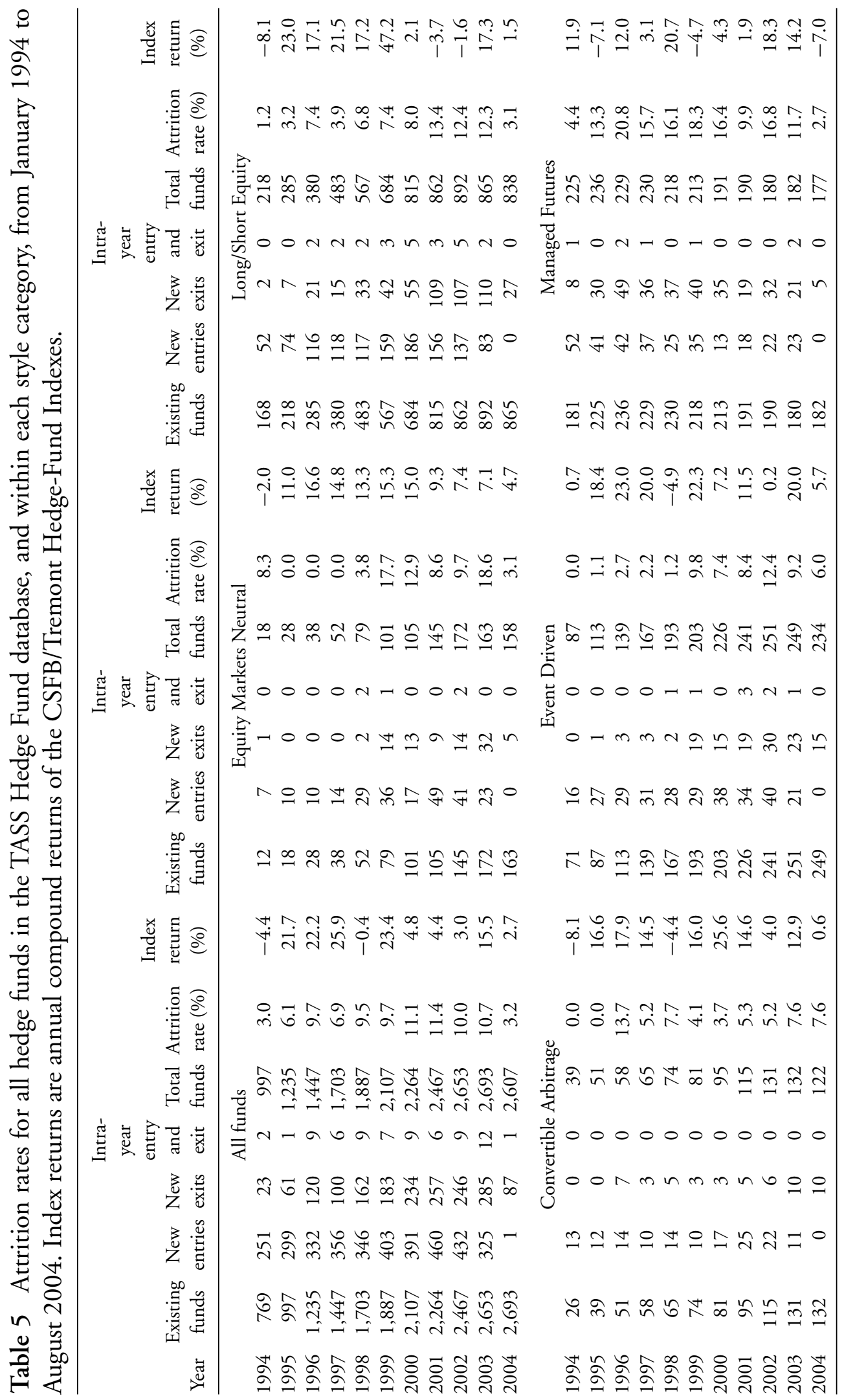




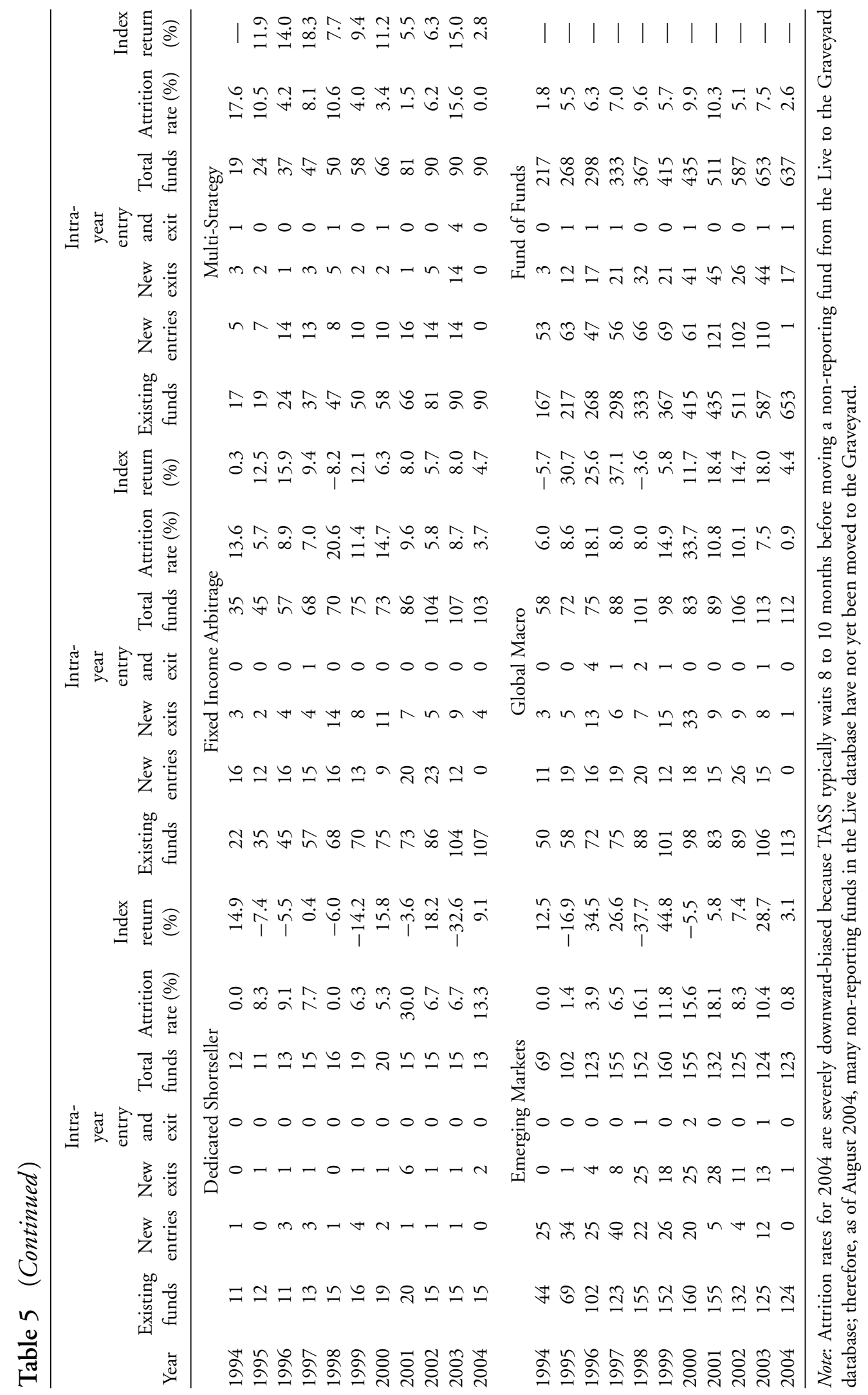




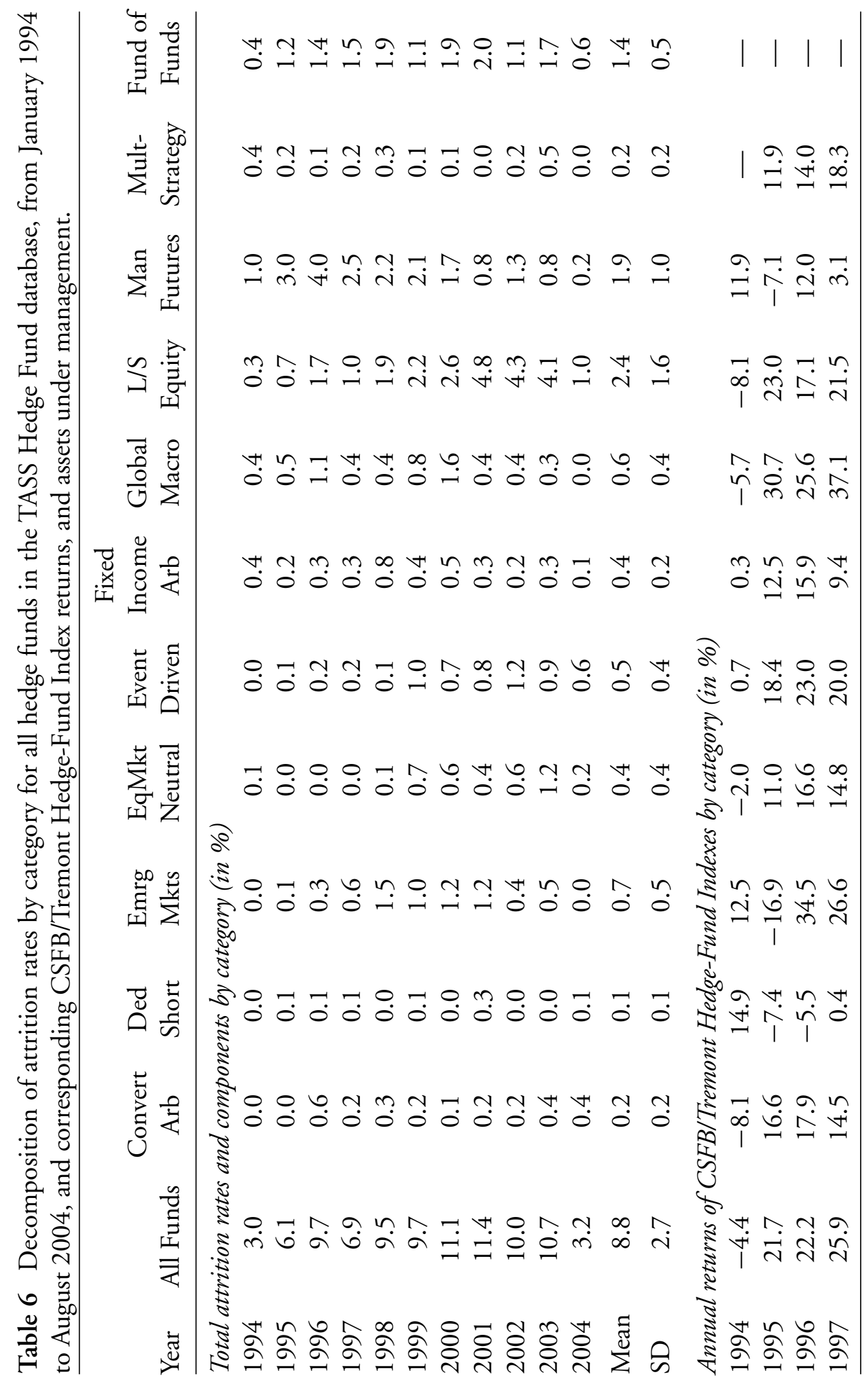




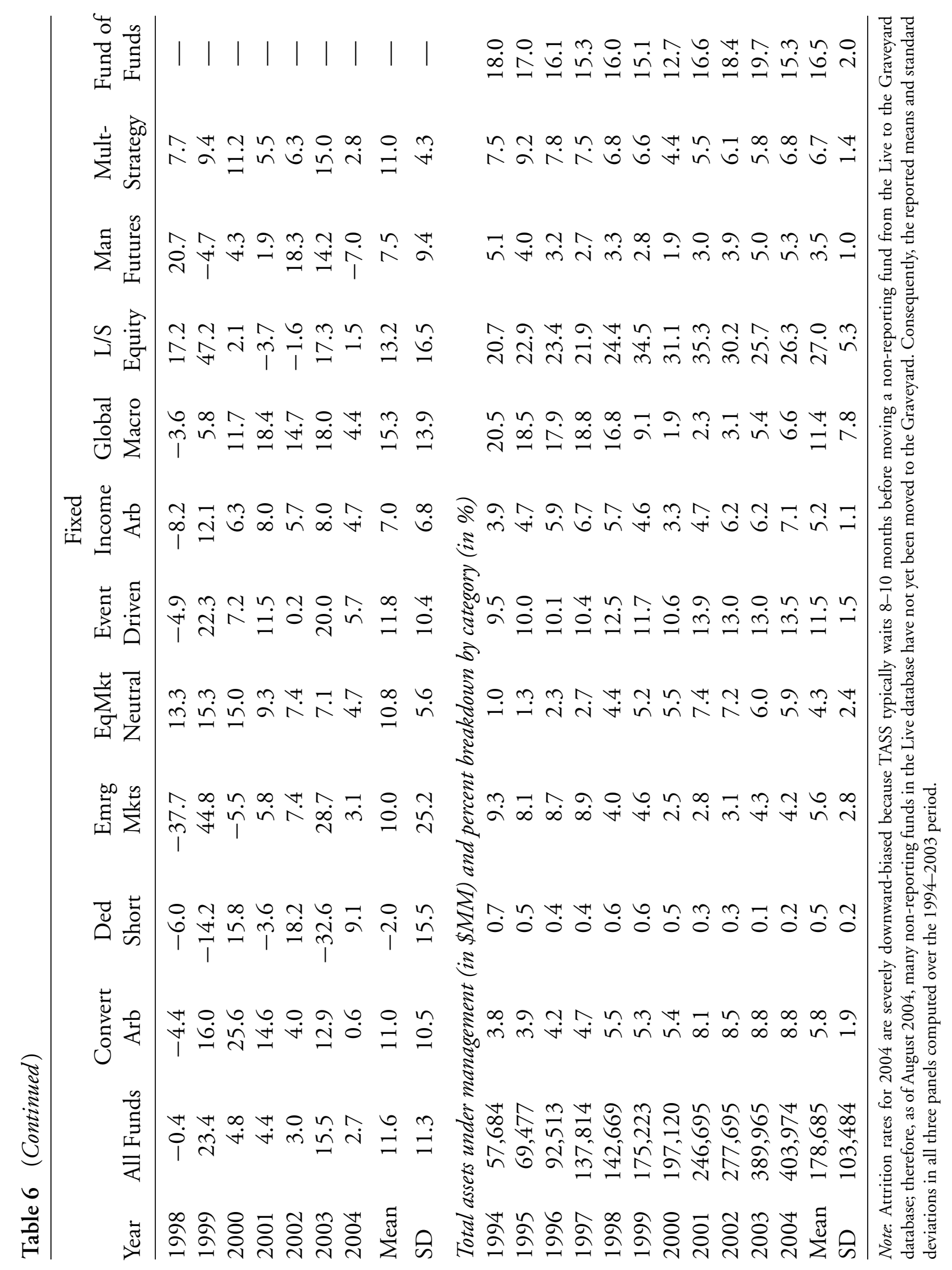




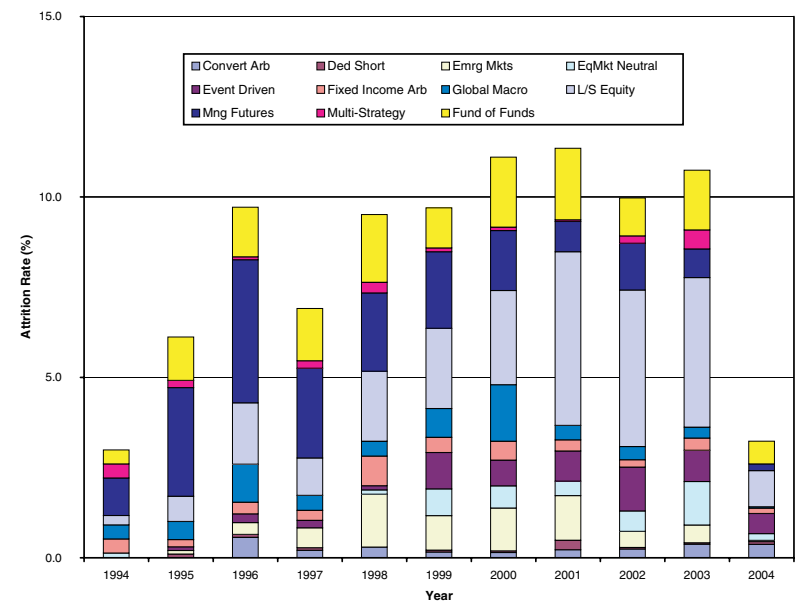

(a)Attrition rates

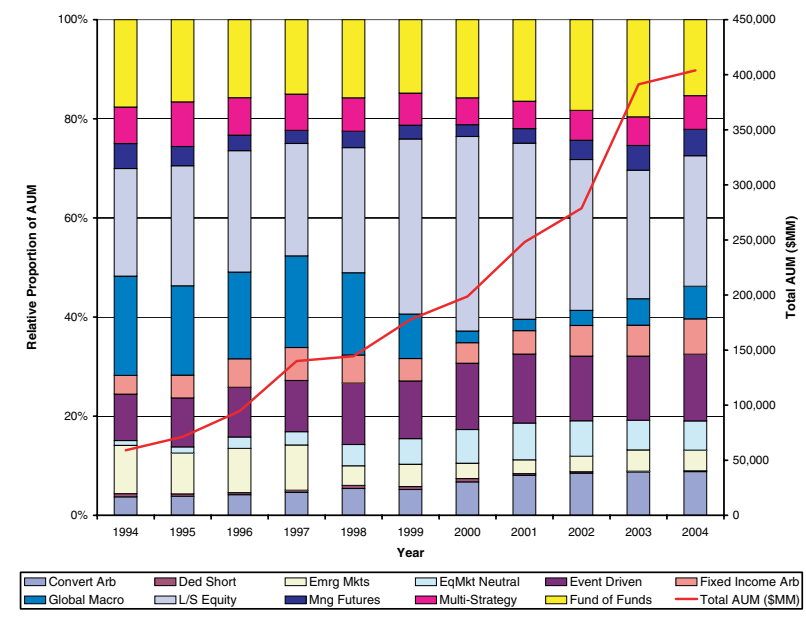

(b)Assets under management

Figure 5 Attrition rates and total assets under management for funds in the TASS Live and Graveyard database from January 1994 to August 2004. Note: the data for 2004 is incomplete, and attrition rates for this year are severely downward biased because of a 8- to 10-month lag in transferring non-reporting funds from the Live to the Graveyard database.

hedge-fund liquidations in their sample-involves the misrepresentation of investments, defined by Feffer and Kundro (2003, p. 5) as "The act of creating or causing the generation of reports and valuations with false and misleading information." Valuation is so central to the proper functioning of financial institutions that the International Association of Financial Engineers - a notfor-profit organization of investment professionals in quantitative finance-convened a special committee to formulate guidelines for best-practices valuation procedures, outlined in a June 2004 white paper (Metzger et al., 2004). The importance of valuation procedures has been underscored recently by the mutual-fund market-timing scandal in which certain investment companies were successfully prosecuted and fined for allowing open-end mutual-fund transactions to occur at stale prices. ${ }^{17}$ By engaging in such transactions, these investment companies were effectively permitting outright wealth transfers from a fund's buy-and-hold shareholders to those engaged in opportunistic buying and selling of shares based on more current information regarding the fund's daily NAVs.

Valuation issues arise mainly when a fund is invested in illiquid assets, i.e., assets that do not trade frequently and cannot easily be traded in large quantities without significant price concessions. For portfolios of illiquid assets, a hedge-fund manager often has considerable discretion in marking the portfolio's value at the end of each month to arrive at the fund's net asset value. Given the nature of hedge-fund compensation contracts and performance statistics, managers may have an incentive to "smooth" their returns by marking their portfolios to less than their actual value in months with large positive returns so as to create a "cushion" for those months with lower returns. Such return-smoothing behavior yields a more consistent set of returns over time, with lower volatility, lower market beta, and a higher Sharpe ratio, but it also produces positive serial correlation as a side effect. ${ }^{18}$ In fact, it is the magnitudes of the serial correlation coefficients of certain types of hedge funds that led Getmansky, Lo, 
and Makarov (2004) to develop their econometric model of smoothed returns and illiquidity exposure. After considering other potential sources of serial correlation-time-varying expected returns, time-varying leverage, and the presence of incentive fees and high-water marks - they conclude that the most plausible explanation is illiquidity exposure and smoothed returns. ${ }^{19}$

We hasten to add that some manager discretion is appropriate and necessary in valuing portfolios, and Getmansky, Lo, and Makarov (2004) describe several other sources of serial correlation in the presence of illiquidity, none of which is motivated by deceit. For example, a common method for determining the fair market value for illiquid assets is to extrapolate linearly from the most recent transaction price (which, in the case of emerging-market debt, might be several months ago), yielding a price path that is a straight line or, at best, a piecewise-linear trajectory. Returns computed from such marks will be smoother, exhibiting lower volatility and higher serial correlation than true economic returns, i.e., returns computed from mark-to-market prices where the market is sufficiently active to allow all available current information to be impounded in the price of the security. For assets that are more easily traded and with deeper markets, mark-to-market prices are more readily available, extrapolated marks are not necessary, and serial correlation is therefore less of an issue. But for assets that are thinly traded, or not traded at all for extended periods of time, marking to market is often an expensive and time-consuming procedure that cannot easily be performed frequently.

Even if a hedge-fund manager does not make use of any form of linear extrapolation to mark the assets in his portfolio, he may still be subject to smoothed returns if he obtains marks from broker-dealers that engage in such extrapolation. For example, consider the case of a conscientious hedge-fund manager attempting to obtain the most accurate mark for his portfolio at month end by getting bid/offer quotes from three independent broker-dealers for every asset in his portfolio, and then marking each asset at the average of the three quote midpoints. By averaging the quote midpoints, the manager is inadvertently downward-biasing price volatility, and if broker-dealers employ linear extrapolation in formulating their quotes (and many do, through sheer necessity because they have little else to go on for the most illiquid assets), or if they fail to update their quotes because of light volume, serial correlation will also be induced in reported returns.

Apart from performance-smoothing concerns, investing in illiquid assets yields additional risk exposures, those involving credit crunches and "flight-to-quality" events. Although liquidity and credit are separate sources of risk exposures for hedge funds and their investors-one type of risk can exist without the other-nevertheless, they have been inextricably intertwined because of the problems encountered by LTCM and many other fixed-income relative-value hedge funds in August and September of 1998.

The basic mechanisms driving liquidity and credit are now familiar to most hedge-fund managers and investors. Because many hedge funds rely on leverage, the size of the positions are often considerably larger than the amount of collateral posted to support those positions. Leverage has the effect of a magnifying glass, expanding small profit opportunities into larger ones, but also expanding small losses into larger losses. When adverse changes in market prices reduces the market value of collateral, credit is withdrawn quickly, and the subsequent forced liquidation of large positions over short periods of time can lead to widespread financial panic, as in the aftermath of the default of Russian government debt in August 1998. Along with the many 
benefits of a truly global financial system is the cost that a financial crisis in one country can have dramatic repercussions in several others.

To quantify the impact of illiquidity risk and smoothed returns, Getmansky, Lo, and Makarov (2004) start by asserting that a fund's true economic returns in month $t$ is given by $R_{t}$, which represents the sum total of all the relevant information that would determine the equilibrium value of the fund's securities in a frictionless market. However, they assume that true economic returns are not observed. Instead, $R_{t}^{o}$ denotes the reported or observed return in period $t$, and let

$$
\begin{aligned}
R_{t}^{o} & =\theta_{0} R_{t}+\theta_{1} R_{t-1}+\cdots+\theta_{k} R_{t-k} \\
\theta_{j} & \in[0,1], \quad j=0, \ldots, k \\
1 & =\theta_{0}+\theta_{1}+\cdots+\theta_{k}
\end{aligned}
$$

which is a weighted average of the fund's true returns $R_{t}$ over the most recent $k+1$ periods, including the current period. This averaging process captures the essence of smoothed returns in several respects. From the perspective of illiquidity-driven smoothing, (1) is consistent with several models in the nonsynchronous trading literature (see Getmansky, Lo, and Makarov, 2004). Alternatively, (1) can be viewed as the outcome of marking portfolios to simple linear extrapolations of acquisition prices when market prices are unavailable, or "mark-to-model" returns where the pricing model is slowly varying through time. And, of course, (1) also captures the intentional smoothing of performance.

The constraint (3) that the weights sum to 1 implies that the information driving the fund's performance in period $t$ will eventually be fully reflected in observed returns, but this process could take up to $k+1$ periods from the time the information is generated. This is a plausible restriction in the current context of hedge funds for several reasons. Even the most illiquid security will trade eventually, and when it does, all of the cumulative information affecting that security will be fully impounded into its transaction price. Therefore, the parameter $k$ should be selected to match the kind of illiquidity of the fund-a fund comprised mostly of exchange-traded US equities would require a much lower value of $k$ than a private equity fund. Alternatively, in the case of intentional smoothing of performance, the necessity of periodic external audits of fund performance imposes a finite limit on the extent to which deliberate smoothing can persist. $^{20}$

Under the smoothing mechanism (1), Getmansky, Lo, and Makarov (2004) show that observed returns have lower variances, lower market betas, and higher Sharpe ratios than true returns. Smoothed returns also exhibit positive serial correlation up to order $k$, and the magnitude of the effect is determined by the pattern of weights $\left\{\theta_{j}\right\}$. If, for example, the weights are disproportionately centered on a small number of lags, relatively little serial correlation will be induced. However, if the weights are evenly distributed among many lags, this will result in higher serial correlation. A useful summary statistic for measuring the concentration of weights is

$$
\xi \equiv \sum_{j=0}^{k} \theta_{j}^{2} \in[0,1]
$$

This measure is well known in the industrial organization literature as the Herfindahl index, a measure of the concentration of firms in a given industry where $\theta_{j}$ represents the market share of firm $j$. Because $\theta_{j} \in[0,1], \xi$ is also confined to the unit interval, and is minimized when all the $\theta_{j}$ are identical, which implies a value of $1 /(k+1)$ for $\xi$, and is maximized when one coefficient is 1 and the rest are 0 , in which case $\xi=1$. In the context of smoothed returns, a lower value of $\xi$ implies more smoothing, and the upper bound of 1 implies no smoothing; hence we shall refer to $\xi$ as a "smoothing index." 
Using the method of maximum-likelihood, Getmansky, Lo, and Makarov (2004) estimate the smoothing model (1)-(3) by estimating an MA(2) process for observed returns assuming normally distributed errors, with the additional constraint that the MA coefficients sum to 1 , and we apply the same procedure to our updated and enlarged sample of funds in the TASS Combined hedge-fund database from February 1977 to August 2004. For purposes of estimating (1), we impose an additional filter on our data, eliminating funds with less than five years of non-missing monthly returns. This leaves a sample of 1,840 funds for which we estimate the MA(2) smoothing model. The maximum-likelihood estimation procedure did not converge for three of these funds, indicating some sort of misspecification or data error, hence we have results for 1,837 funds: 1,226 in the Live database and 611 in the Graveyard database. $^{21}$

Table 7 contains summary statistics for the maximum-likelihood estimate of the smoothing parameters $\left(\theta_{0}, \theta_{1}, \theta_{2}\right)$ and smoothing index $\xi$ for both databases. Five categories have smaller average values of $\xi$ than the others in the Live database: Convertible Arbitrage (0.635), Emerging Markets (0.723), Event Driven (0.665), Fixed Income Arbitrage (0.686), Long/Short Equity (0.838), and Multi-Strategy (0.663). To determine the statistical significance of these averages, Table 7 reports $z$-statistics which are asymptotically standard normal under the null hypothesis that $\xi=1$; hence, values greater than 1.96 indicate significance at the $95 \%$ level, ${ }^{22}$ and these six categories yield average smoothing indexes that are statistically significant at the $99 \%$ level. These results coincide with common intuition about the nature of these five categories-they do invest in rather illiquid securities, in contrast to funds in the other categories such as Dedicated Shortsellers and Managed Futures, both of which involve particularly liquid securities by the nature of their investment mandate. ${ }^{23}$
Table 7 shows that similar patterns hold for funds in the Graveyard database. Five out of the six categories exhibit statistically significant smoothing indexes, the exception being the last category, Multi-Strategy, with an average smoothing index of 0.960 for Graveyard funds versus 0.663 for Live funds. However, there are only eight funds of this type in the Graveyard database as compared to 39 funds in the Live database, hence the sample may be too small to draw inferences with any degree of confidence.

A comparison of the degree of smoothing between Live and Graveyard funds in these five categories yields mixed results: for Emerging Markets, Event Driven, and Long/Short Equity, the Live funds yield smaller smoothing indexes, but for Convertible Arbitrage and Fixed-Income Arbitrage, the Graveyard funds exhibit a somewhat greater degree of average smoothing. A scatterplot of smoothingindex estimates for Live and Graveyard funds is given in Figure 6, and a visual comparison suggests that there is little difference in illiquidity risk across Live and Graveyard funds. However, the histograms of smoothing indexes $\xi$ and smoothing coefficients $\theta_{0}$ in Figure 7 tell a very different story. These histograms show that the distributions of the two smoothing measures for Live funds are more heavily weighted in the left tails than for Graveyard funds.

There are at least three possible explanations for this difference. One is that Live funds are, by definition, more successful at controlling risk and, as a result, do tend to have smoother returns. Another interpretation is that funds with smoother returns are more attractive to investors and, therefore, have greater staying power. A third possibility is that funds with more illiquidity risk are, on average, compensated for bearing such risk, which in turn implies stronger performance and greater asset-gathering abilities. With additional information about the specific investment process of a given fund, e.g., the 


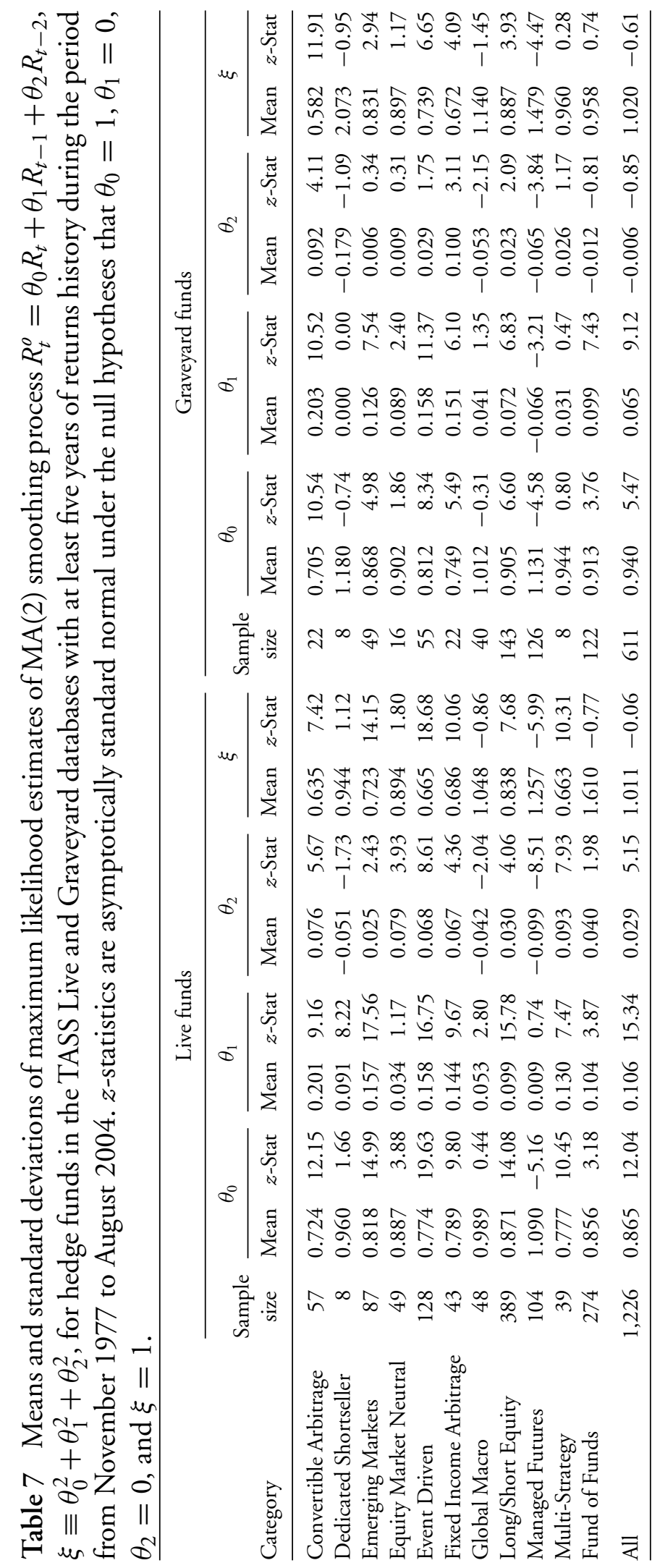




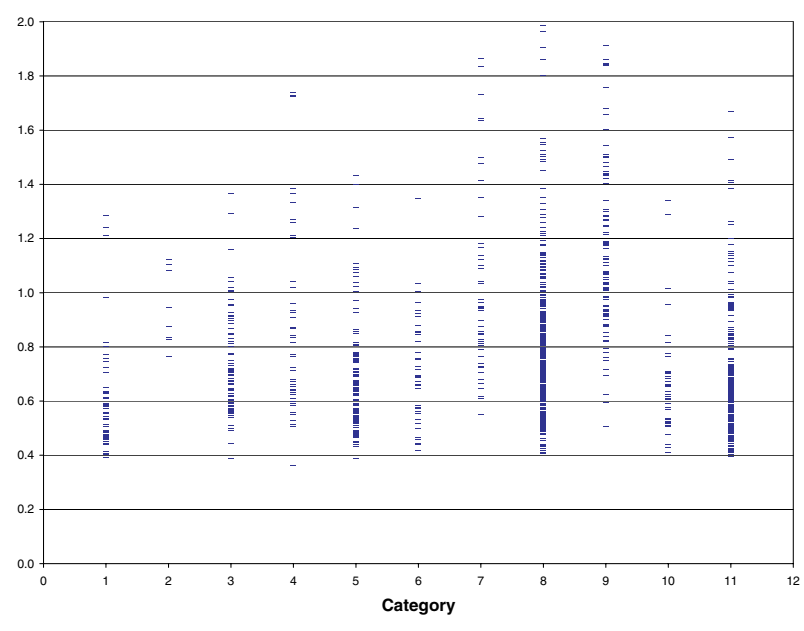

(a) Smoothing index $\xi$ for Live funds

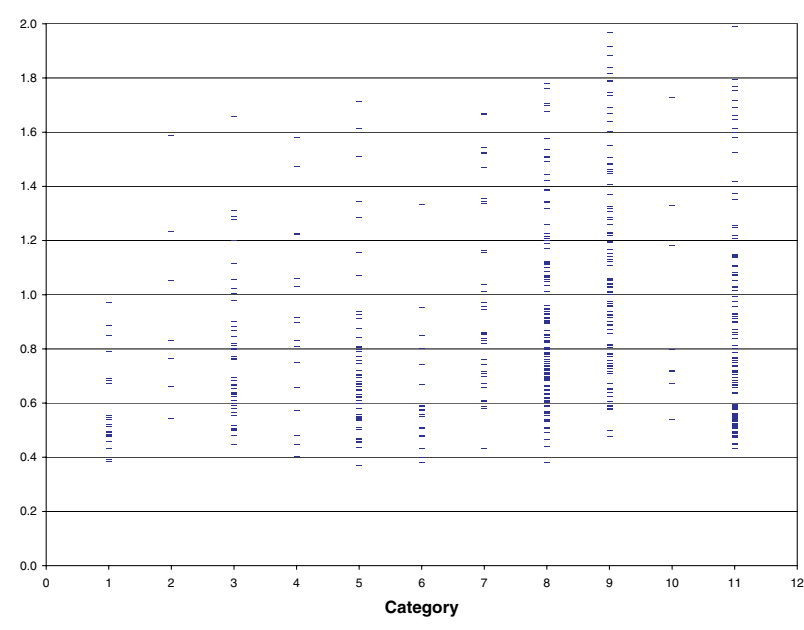

(b) Smoothing index $\xi$ for Graveyard funds

Figure 6 Smoothing index estimates $\xi$ by category for hedge funds in the TASS Live and Graveyard databases with at least five years of returns history during the period from November 1977 to August 2004. Category definitions: $1=$ Convertible Arbitrage, $2=$ Dedicated Short Bias, $3=$ Emerging Markets, $4=$ Equity Market-Neutral, $5=$ Event Driven, $6=$ Fixed-Income Arbitrage, $7=$ Global Macro, $8=$ Long/Short Equity, $9=$ Managed Futures, $10=$ Multi-Strategy, $11=$ Fund of Funds.

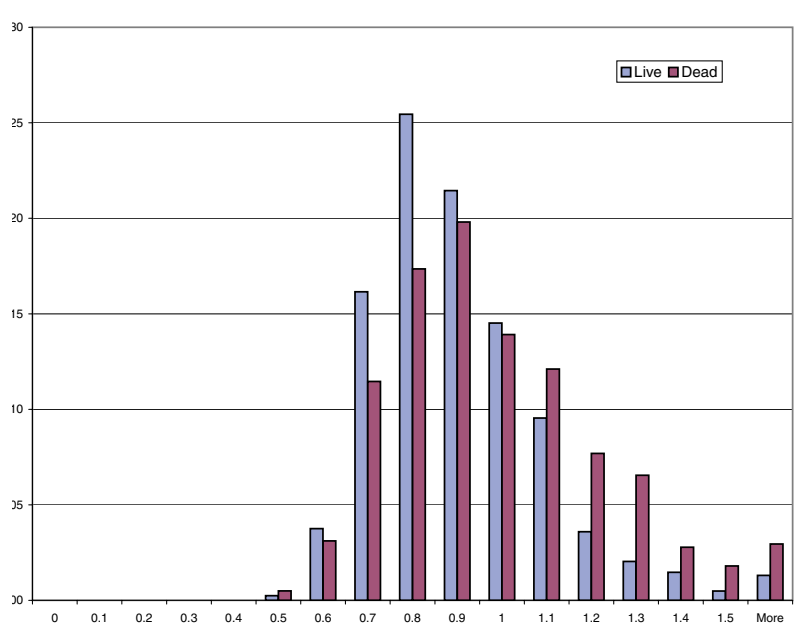

(a) Smoothing parameter $\theta_{0}$

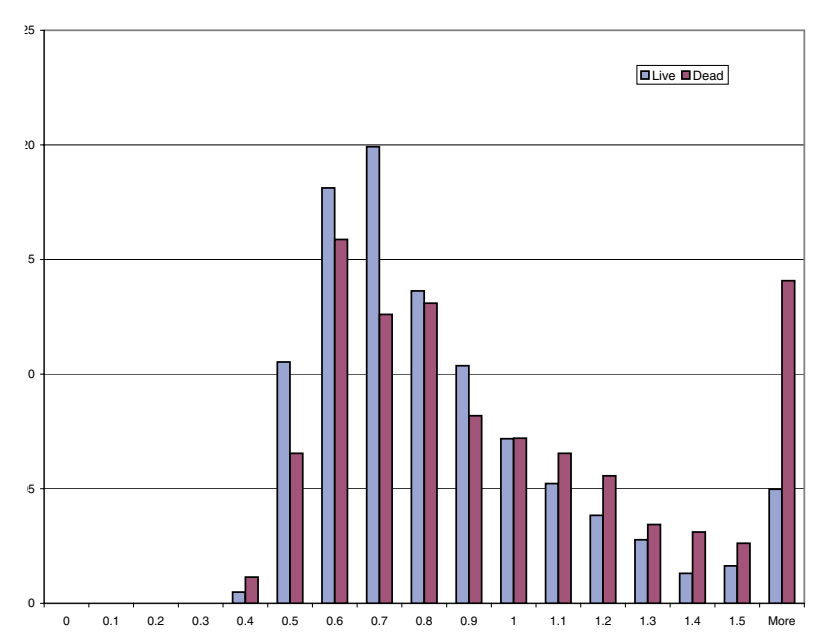

(b) Smoothing index $\xi$

Figure 7 Histograms of estimated smoothing parameters $\theta_{0}$ and smoothing indexes $\xi$ for hedge funds in the TASS Live and Graveyard databases with at least five years of returns history during the period from November 1977 to August 2004.

fund prospectus and an investment due-diligence meeting, it may be possible for an investor to determine which one of these three explanations is most likely to apply on a case-by-case basis.
Of course, in contrast to cases of fraud, there is nothing inappropriate about hedge funds taking on illiquidity risk as long as such risk is properly disclosed. In fact, from both theoretical and empirical 
perspectives, significant rewards accrue to investors willing to bear illiquidity risk (see, for example: Ibbotson Associates, 2004; Lo, Mamaysky, and Wang, 2004). Moreover, the willingness of certain investors to bear such risks has created considerable social value in allowing those who cannot afford such risks to shed them at reasonable cost. However, proper disclosure is critical in this case because the nuances of illiquidity risk are more subtle than traditional market risks, and not all investors are fully equipped to evaluate them. Despite considerable progress in the recent literature in modeling both credit and illiquidity risk, ${ }^{24}$ the complex network of creditor/obligor relationships, revolving credit agreements, and other financial interconnections is largely unmapped. Perhaps some of the newly developed techniques in the mathematical theory of networks will allow us to construct systemic measures for liquidity and credit exposures and the robustness of the global financial system to idiosyncratic shocks. The "small-world" networks considered by Watts and Strogatz (1998) and Watts (1999) seem to be particularly promising starting points.

\section{Conclusions}

The TASS Graveyard database reminds us that not too long ago, hedge funds were a cottage industry, with rapid turnover and many small startupshalf of all liquidated funds never reach their fourth anniversary, and the median assets under management for funds in the Graveyard is just over $\$ 6$ million. Performance is a significant driver of liquidations, with Graveyard funds generally exhibiting lower average returns and higher volatilities. Graveyard funds also seem to exhibit less illiquidity exposure as measured by serial correlation and the MA(2) smoothed-returns model of Getmansky, Lo, and Makarov (2004). Certain investment styles such as Managed Futures and Global Macro are prone to higher attrition rates, presumably because of their higher risk levels, and the recent increase in attrition rates for Long/Short Equity funds is a potential source of concern because of the large number of funds in this category and the amount of assets involved. More generally, the apparent inverse relation between performance and attrition rates implies some interesting patterns in the dynamics of the hedge-fund industry, where strategies and hedge-fund style-categories will wax and wane according to strategy returns, with potentially significant implications for market efficiency, as outlined in Farmer and Lo (1999) and Lo (2004). Whether these dynamics are intrinsic to the markets in which hedge funds invest, or created by the repercussions of major fund flows into and out of the industry, is still an open question. But in either case, they imply serious business risks for managers and investors alike.

Despite the wealth of statistical information that the TASS database provides, it is silent on a great many issues surrounding the liquidation of hedge funds. For example, unlike the hand-collected sample of funds in Feffer and Kundro's (2003) study, we do not know the details of each Graveyard fund's liquidation, hence we cannot tell whether macroeconomic events are more important than operational risks in determining a hedge fund's fate. The historical lack of transparency of the hedgefund industry, coupled with the fact that it is still largely unregulated, suggests that a comprehensive analysis of hedge-fund liquidations is difficult to complete in the near term. The great heterogeneity of the hedge-fund industry, even within a particular style category, makes it all the more challenging to draw specific inferences from existing data sources.

However, there is reason to be cautiously optimistic. The recent influx of assets from institutional investors-who require greater transparency to carry out their fiduciary obligations - is inducing hedge funds to be more forthcoming. Also, the regulatory environment is shifting rapidly. In particular, the US Securities and Exchange Commission 
(SEC) recently voted to require hedge funds to register as investment advisers under the Investment Advisers Act of 1940 (Rule 203(b)(3)-2). This proposal has generated considerable controversy, with compelling arguments on both sides of the debate and a 3-to-2 split vote among the commissioners. While registration might provide an additional layer of protection for investors, the costs of registration are substantial-both for the SEC and for many smaller hedge funds - which may stifle the growth of this vibrant industry.

Nevertheless, registering hedge funds may not be sufficient, especially if the goal is to protect the general public and promote the long-run health of the financial services industry. Registration requires filing certain information with the SEC on a regular basis and being subject to periodic on-site examinations, but the kind of information required does not necessarily address the main concern that hedge funds pose for the financial system: are hedge funds engaged in activities that can destabilize financial markets and cause widespread dislocation throughout the industry? This concern was first brought to public awareness in August 1998 when the default of Russian government debt triggered a global "flight to quality" that caught many hedge funds by surprise. One of the most significant players in this market, LTCM, lost most of its multi-billiondollar capital base in a matter of weeks. Ultimately, LTCM was bailed out by a consortium organized by the Federal Reserve Bank of New York because its collapse might have set off a chain reaction of failures of other major financial institutions.

The possibility of a "domino effect" in the hedgefund industry is one of the most important revelations to have come out of the LTCM debacle.

Prior to August 1998, vulnerabilities in the global financial system involved stock market crashes, bank runs, and hyperinflation-otherwise known as "systemic risk" - were largely the province of central bankers and finance ministers. Such events were rare but generally well understood, as in the case of the Asian Crisis of 1997 in which overleveraged financial institutions and weak corporate governance led to a series of currency devaluations, stock market crashes, and defaults in Korea, Thailand, Indonesia, and other Asian countries. However, with the collapse of LTCM, a new source of systemic risk was born: the hedge fund. Given how little is known about these unregulated entities, a natural reaction to August 1998 is to regulate them. However, the specific information about LTCM's activities that might have helped regulators and investors to avoid the stunning losses of 1998 - the fund's leverage, the number of credit lines available to the fund, the vulnerability of those credit lines during extreme market conditions, and the degree to which other funds had similar positions-is currently not required of registered investment advisers.

Apart from the costs and benefits of requiring hedge funds to register, it is clear that a different approach is needed to address the larger issue of systemic risk posed by hedge funds. We propose two specific innovations: a database of more detailed information about hedge funds and associated financial institutions to be collected and maintained by the SEC, and a separate unit within the SEC charged with the responsibility of conducting forensic examinations and providing publicly available summary reports in the wake of unintentional hedge-fund liquidations.

Without data, it is virtually impossible for regulators to engage in any meaningful over-sight of the hedge-fund industry. An example of the importance of data for regulatory oversight is event analysisone of the most powerful tools for detecting insider trading-in which the statistical properties of stockprice movements are compared before, during, and after the release of material information regarding the stock. Unusual price movements prior to the 
release of material information sometimes signals an information leak, which can then be verified or refuted by a more detailed investigation. Without historical price data, the SEC's Division of Enforcement would lose its ability to monitor thousands of publicly traded securities simultaneously and in a timely fashion, making it virtually impossible for the SEC to enforce insider-trading laws broadly given the current size of its staff.

Regulators should have access to the following information from all hedge funds: monthly returns, leverage, assets under management, fees, instruments traded, and all brokerage, financing, and credit relationships. In addition, regulators should collect similar information from prime brokers, banks, and other hedge-fund counterparties, as well as information about the capital adequacy of these financial institutions, as they are likely to be among the first casualties in any systemic event involving hedge funds. This information should be archived so that over time, a complete historical database is developed and the dynamics of each entity and the industry can be tracked and measured.

There is, of course, a privacy issue regarding such highly confidential data that must be properly addressed. Unlike publicly traded companies such as mutual funds, which are required to disclose a great deal of information because they are selling their securities to the general public, hedge funds are private partnerships that can solicit only a limited clientele: investors who are deemed to be sophisticated and able to tolerate significant financial risks. As a result, managers willing to provide greater disclosure may choose a public offering such as a mutual fund, and those preferring opacity may choose instead to form a hedge fund. This menu of choices has great social benefits in providing a wider range of alternatives to suit different preferences and markets, and should not be limited. However, it is possible to collect and analyze hedgefund data while protecting the confidentiality of all parties concerned, as illustrated by the relationship between US banks and the Office of the Comptroller of the Currency.

In addition to serving as a repository for hedgefund data, the SEC can play an even more valuable role in reducing systemic risk by investigating and producing public reports of hedge-fund liquidations. Although there may be common themes in the demise of many hedge funds - too much leverage, too concentrated a portfolio, operational failures, securities fraud, or insufficient assets under management - each liquidation has its own unique circumstances and is an opportunity for the hedgefund industry to learn and improve. We need look no further than the National Transportation Safety Board (NTSB) for an excellent and practical role model of an investigative unit specifically designed to provide greater transparency and improve public safety.

In the event of an airplane crash, the NTSB assembles a team of engineers and flight-safety experts who are immediately dispatched to the crash site to conduct a thorough investigation, including interviewing witnesses, poring over historical flight logs and maintenance records, and sifting through the wreckage to recover the flight recorder or "black box" and, if necessary, reassembling the aircraft from its parts so as to determine the ultimate cause of the crash. Once its work is completed, the NTSB publishes a report summarizing the team's investigation, concluding with specific recommendations for avoiding future occurrences of this type of accident. The report is entered into a searchable database that is available to the general public (see http://www.ntsb.gov/ntsb/query.asp) and this has been one of the major factors underlying the remarkable safety record of commercial air travel.

For example, it is now current practice to spray airplanes with de-icing fluid just prior to take-off 
when the temperature is near freezing and it is raining or snowing. This procedure was instituted in the aftermath of USAir Flight 405's crash on March 22, 1992. Flight 405 stalled just after becoming airborne because of ice on its wings, despite the fact that de-icing fluid was applied before it left its gate. Apparently, Flight 405's take-off was delayed because of air traffic, and ice re-accumulated on its wings while it waited for a departure slot on the runway in the freezing rain. The NTSB Aircraft Accident Report AAR-93/02-published on February 17, 1993 and available through several internet sites - contains a sobering summary of the NTSB's findings (Report AAR-93/02, page vi):

The National Transportation Safety Board determines that the probable cause of this accident were the failure of the airline industry and the Federal Aviation Administration to provide flightcrews with procedures, requirements, and criteria compatible with departure delays in conditions conducive to airframe icing and the decision by the flightcrew to take off without positive assurance that the airplane's wings were free of ice accumulation after 35 minutes of exposure to precipitation following de-icing. The ice contamination on the wings resulted in an aerodynamic stall and loss of control after liftoff. Contributing to the cause of the accident were the inappropriate procedures used by, and inadequate coordination between, the flightcrew that led to a takeoff rotation at a lower than prescribed air speed.

The safety issues in this report focused on the weather affecting the flight, US-Air's de-icing procedures, industry airframe de-icing practices, air traffic control aspects affecting the flight, USAir's takeoff and preflight procedures, and flightcrew qualifications and training. The dynamics of the airplane's impact with the ground, postaccident survivability, and crash/fire/rescue activities were also analyzed.

Current de-icing procedures have no doubt saved many lives thanks to NTSB Report AAR-93/02, but this particular innovation was paid for by the lives of the 27 individuals who did not survive the crash of Flight 405. Imagine the waste if the NTSB did not investigate this tragedy and produce concrete recommendations to prevent this from happening again.
Hedge-fund liquidations are, of course, considerably less dire, generally involving no loss of life. However, as more pension funds make allocations to hedge funds, and as the "retailization" of hedge funds continues, losses in the hedge-fund industry may have more signifficant implications for individual investors, in some cases threatening retirement wealth and basic living standards. Moreover, the spillover effects of an industry-wide shock to hedge funds should not be under-estimated, as the events surrounding LTCM in the Fall of 1998 illustrated. For these reasons, an SEC-sponsored organization dedicated to investigating, reporting, and archiving the "accidents" of the hedgefund industry-and the financial services sector, more generally - may yield significant social benefits in much the same way that the NTSB has improved transportation safety enormously for all air travellers. By maintaining teams of experienced professionals-forensic accountants, financial engineers from industry and academia, and securities and tax attorneys - that work together on a regular basis to investigate a number of hedge-fund liquidations, the SEC would be able to determine quickly and accurately how each liquidation came about, and the resulting reports would be an invaluable source of ideas for improving financial markets and avoiding future liquidations of a similar nature. ${ }^{25}$

The establishment of an NTSB-like organization within the SEC will not be inexpensive. Currently, the SEC is understaffed and overburdened, and this is likely to worsen now that all hedge funds are required to register under the Investment Advisers Act of 1940. In addition, the lure of the private sector makes it challenging for government agencies to attract and retain individuals with expertise in these highly employable fields. Individuals trained in forensic accounting, financial engineering, and securities law now command substantial premiums on Wall Street over government pay scales. Although the typical SEC employee is likely to be 
motivated more by civic duty than financial gain, it would be unrealistic to build an organization on altruism alone.

The cost of an SEC-based "Capital Markets Safety Board" is more than justified by the valuable lessons that would be garnered from a systematic analysis of financial incidents and the public dissemination of recommendations by seasoned professionals that review multiple cases each year. The benefits would accrue not only to the wealthy-which is currently how the hedge-fund industry is tilted-but would also flow to retail investors in the form of more stable financial markets, greater liquidity, reduced borrowing and lending costs as a result of decreased systemic risk exposures, and a wider variety of investment choices available to a larger segment of the population because of increased transparency, oversight, and, ultimately, financial security. It is unrealistic to expect that market crashes, panics, collapses, and fraud will ever be completely eliminated from our capital markets, but we should avoid compounding our mistakes by failing to learn from them.

\section{Acknowledgments}

Research support from AlphaSimplex Group and the MIT Laboratory for Financial Engineering is gratefully acknowledged. We thank Gifford Fong and Svetlana Sussman for helpful comments and Sunil Aggarwal, Neil Desai, and Maria Simona Jelescu for research assistance.

\section{Appendix}

The following is a list of category descriptions, taken directly from TASS documentation, that define the criteria used by TASS in assigning funds in their database to one of 11 possible categories:
Convertible Arbitrage This strategy is identified by hedge investing in the convertible securities of a company. A typical investment is to be long the convertible bond and short the common stock of the same company. Positions are designed to generate profits from the fixed income security as well as the short sale of stock, while protecting principal from market moves.

Dedicated Shortseller Dedicated shortsellers were once a robust category of hedge funds before the long bull market rendered the strategy difficult to implement. A new category, short biased, has emerged. The strategy is to maintain net short as opposed to pure short exposure. Short biased managers take short positions in mostly equities and derivatives. The short bias of a manager's portfolio must be constantly greater than zero to be classified in this category.

Emerging Markets This strategy involves equity or fixed income investing in emerging markets around the world. Because many emerging markets do not allow shortselling, nor offer viable futures or other derivative products with which to hedge, emerging market investing often employs a long-only strategy.

Equity Market Neutral This investment strategy is designed to exploit equity market inefficiencies and usually involves being simultaneously long and short matched equity portfolios of the same size within a country. Market neutral portfolios are designed to be either beta or currency neutral, or both. Well-designed portfolios typically control for industry, sector, market capitalization, and other exposures. Leverage is often applied to enhance returns.

Event Driven This strategy is defined as "special situations" investing designed to capture price movement generated by a significant pending corporate event such as a merger, corporate restructuring, liquidation, bankruptcy or reorganization. There are 
three popular sub-categories in event-driven strategies: risk (merger) arbitrage, distressed/high yield securities, and Regulation D.

Fixed Income Arbitrage The fixed income arbitrageur aims to profit from price anomalies between related interest rate securities. Most managers trade globally with a goal of generating steady returns with low volatility. This category includes interest rate swap arbitrage, US and non-US government bond arbitrage, forward yield curve arbitrage, and mortgage-backed securities arbitrage. The mortgage-backed market is primarily USbased, over-the-counter and particularly complex.

Global Macro Global macro managers carry long and short positions in any of the world's major capital or derivative markets. These positions reflect their views on overall market direction as influenced by major economic trends and/or events. The portfolios of these funds can include stocks, bonds, currencies, and commodities in the form of cash or derivatives instruments. Most funds invest globally in both developed and emerging markets.

Long/Short Equity This directional strategy involves equity-oriented investing on both the long and short sides of the market. The objective is not to be market neutral. Managers have the ability to shift from value to growth, from small to medium to large capitalization stocks, and from a net long position to a net short position. Managers may use futures and options to hedge. The focus may be regional, such as long/short US or European equity, or sector specific, such as long and short technology or healthcare stocks. Long/short equity funds tend to build and hold portfolios that are substantially more concentrated than those of traditional stock funds.

Managed Futures This strategy invests in listed financial and commodity futures markets and currency markets around the world. The managers are usually referred to as Commodity Trading Advisors, or CTAs. Trading disciplines are generally systematic or discretionary. Systematic traders tend to use price and market specific information (often technical) to make trading decisions, while discretionary managers use a judgmental approach.

Multi-Strategy The funds in this category are characterized by their ability to dynamically allocate capital among strategies falling within several traditional hedge fund disciplines. The use of many strategies, and the ability to reallocate capital between them in response to market opportunities, means that such funds are not easily assigned to any traditional category.

The Multi-Strategy category also includes funds employing unique strategies that do not fall under any of the other descriptions.

Fund of Funds A "Multi Manager" fund will employ the services of two or more trading advisors or Hedge Funds who will be allocated cash by the Trading Manager to trade on behalf of the fund.

\section{Notes}

1 See Armitstead (2004).

2 See Atkins and Hays (2004).

3 Using merged data from three vendors-TASS, HFR, and ZCM/MAR_from 1994 to 2000, Agarwal, Daniel, and Naik (2004, Figure 1) show that only $10 \%$ of their sample of 1776 live and 1655 inactive funds are common to all three databases.

4 These databases typically refer requests for prospectuses to the funds themselves so that each fund is responsible for discharging its legal responsibility to determine whether or not an individual requesting fund documents is indeed a "qualified investor."

5 Each fund is assigned a numerical code, and only qualified investors are given the mapping from codes to fund names.

6 These studies use different databases, which may explain the variation in their estimates. However, Liang (2000) and Agarwal, Daniel, and Naik (2004) show that several of these databases do have some funds in common (see note 3$)$. 
7 The lack of transparency and the unregulated status of most hedge funds are significant barriers to any systematic data collection effort, hence it is difficult to draw inferences about industry norms.

8 For further information about these data, see http:// www.tremont.com.

9 TASS has adopted a policy of transferring funds from the Live to the Graveyard database if they do not report returns for an 8- to 10-month period.

10 For studies attempting to quantify the degree and impact of survivorship bias, see Baquero, Horst, and Verbeek (2002), Brown et al. (1992) and Brown, Goetzmann, and Park (1999, 2001a,b), Carpenter and Lynch (1999), Fung and Hsieh (1997b, 2000), Horst, Nijman, and Verbeek (2001), Hendricks, Patel, and Zeckhauser (1997), and Schneeweis and Spurgin (1996).

11 TASS defines returns as the change in net asset value during the month (assuming the reinvestment of any distributions on the reinvestment date used by the fund) divided by the net asset value at the beginning of the month, net of management fees, incentive fees, and other fund expenses. Therefore, these reported returns should approximate the returns realized by investors. TASS also converts all foreign-currency denominated returns to US-dollar returns using the appropriate exchange rates.

12 See the references in note 10 .

13 Of the 1,765 funds in the Graveyard database, four funds did not have status codes assigned; hence we coded them as 9's ( "Unknown"). They are 3,882 (Fund of Funds), 34053 (Managed Futures), 34053 (Managed Futures), 34054 (Managed Futures), 34904 (Long/Short Equity).

14 The $k^{\text {th }}$ order autocorrelation or "serial correlation" coefficient $\rho_{k}$ is defined as $\rho_{k} \equiv \operatorname{Cov}\left[R_{t}, R_{t-k}\right] / \operatorname{Var}\left[R_{t}\right]$, which is simply the correlation coefficient between month t's return and month $t-k$ 's return.

15 Recall that TASS launched their Graveyard database in 1994 , hence this is the beginning of our sample for Table 5 .

16 We do not include 2004 in this average because TASS typically waits 8 to 10 months before moving a nonreporting fund from the Live to the Graveyard database. Therefore, the attrition rate is severely downward biased for 2004 since the year is not yet complete, and many non-reporting funds in the Live database have not yet been classified as Graveyard funds. Also, note that there is only one new fund in 2004-this figure is grossly downward-biased as well. Hedge funds often go through an "incubation period" where managers trade with limited resources to develop a track record. If successful, the manager will provide the return stream to a database vendor like
TASS, and the vendor usually enters the entire track record into the database, providing the fund with an "instant history." According to Fung and Hsieh (2000), the average incubation period-from a fund's inception to its entry into the TASS database-is one year.

17 See Boudoukh et al. (2002) for a more detailed discussion of the mutual-fund timing issue.

18 Asness, Krail, and Liew (2001) were perhaps the first to document the fact that certain "market neutral" hedge funds had significant beta exposure but with respect to lagged market returns. Getmansky, Lo, and Makarov (2004) show that this phenomenon is consistent with illiquidity exposure and smoothed returns.

19 Although illiquidity and smoothed returns are two distinct phenomena, one facilitates the other-for highly liquid securities, both theory and empirical evidence suggest their returns are unlikely to be very smooth. Indeed, as a practical matter, if the assets in the manager's portfolio are actively traded, the manager has little discretion in marking the portfolio. The more illiquid the portfolio, the more latitude the manager has in determining its value, e.g., discretionary accruals for unregistered private placements and venture capital investments. In fact, Chandar and Bricker (2002) conclude that managers of certain closed-end mutual funds use accounting discretion to manage fund returns around a passive benchmark.

20 In fact, if a fund allows investors to invest and withdraw capital only at pre-specified intervals, imposing lock-ups in between, and external audits are conducted at these same pre-specified intervals, then it may be argued that performance smoothing is irrelevant. For example, no investor should be disadvantaged by investing in a fund that offers annual liquidity and engages in annual external audits with which the fund's net-asset-value is determined by a disinterested third party for purposes of redemptions and new investments. However, there are at least two additional concerns that remain-historical track records and estimates of a fund's liquidity exposure are both affected by smoothed returns - and they are important factors in the typical hedge-fund investor's overall investment process. Moreover, given the questions surrounding the role that the auditors at Arthur Andersen played in the Enron affair, there is the further concern of whether third-party auditors are truly objective and free of all conflicts of interest.

21 The reference numbers for the funds that did not yield maximum-likelihood estimates are 1018, 1405, and 4201.

22 Specifically, if $\bar{\xi}$ is the average smoothing index for all funds in a given category, then $z \equiv(1-\bar{\xi}) / \operatorname{se}(\bar{\xi})$ where $\operatorname{se}(\bar{\xi})$ is the standard error of $\bar{\xi}$, given by the cross-sectional 
standard deviation of all the individual estimates of $\xi$ divided by the square root of the number of funds in the sample. This assumes that the individual estimates of $\xi$ are independently and identically distributed, which may not be a good approximation for funds within a given category. In these cases, robust standard errors can be computed. Nevertheless, the relative rankings of the $z$-statistics across categories may still contain useful information.

23 Futures contracts are, by definition, more liquid than the underlying spot, and the ability to shortsell a security implicitly requires a certain degree of liquidity.

24 See, for example, Bookstaber $(1999,2000)$ and Kao (2000), and their citations.

25 Formal government investigations of major financial events do occur from time to time, as in the April 1999 Report of the President's Working Group in Financial Markets on Hedge Funds, Leverage, and the Lessons of Long-Term Capital Management. However, this inter-agency report was put together on an ad hoc basis with committee members that had not worked together previously and regularly on forensic investigations of this kind. With multiple agencies involved, and none in charge of the investigation, the administrative overhead becomes more significant. Although any thorough investigation of the financial services sector is likely to involve the SEC, the CFTC, the US Treasury, and the Federal Reserve-and inter-agency cooperation should be promoted-there are important operational advantages in tasking a single office with the responsibility for coordinating all such investigations and serving as a repository for the expertise in conducting forensic examinations of financial incidents.

\section{References}

Ackermann, C., McEnally, R., and Ravenscraft, D. (1999). "The Performance of Hedge Funds: Risk, Return, and Incentives." Journal of Finance 54, 833-874.

Agarwal, V. and Naik, N. (2000a). "Performance Evaluation of Hedge Funds with Buy-and-Hold and OptionBased Strategies." Hedge Fund Centre Working Paper No. HF-003, London Business School.

Agarwal, V. and Naik, N. (2000b). "On Taking the 'Alternative' Route: The Risks, Rewards, and Performance Persistence of Hedge Funds." Journal of Alternative Investments 2, 6-23.

Agarwal, V. and Naik, N. (2000c). "Multi-Period Performance Persistence Analysis of Hedge Funds Source.” Journal of Financial and Quantitative Analysis 35, 327-342.
Agarwal, V. and Naik, N. (2000d). "Generalized Style Analysis of Hedge Funds.” Journal of Asset Management 1, 93-109.

Agarwal, V. and Naik, N. (2004). "Risks and Portfolio Decisions Involving Hedge Funds.” Review of Financial Studies 17, 63-98.

Agarwal, V., Daniel, N., and Naik, N. (2004). "Flows, Performance, and Managerial Incentives in the Hedge Fund Industry." Working Paper, Georgia State University.

Amin, G. and Kat, H. (2003a). "Hedge Fund Performance 1990-2000: Do the Money Machines Really Add Value?" Journal of Financial and Quantitative Analysis 38, 251-274.

Amin, G. and Kat, H. (2003b). "Welcome to the Dark Side: Hedge Fund Attrition and Survivorship Bias over the Period 1994-2001." Journal of Alternative Investments 6, 57-73.

Amin, G. and Kat, H. (2003c). "Stocks, Bonds, and Hedge Funds." Journal of Portfolio Management 29, 113-119.

Armitstead, L. (2004). "Dalman Stakes His Own Cash on Hedge Fund." UK Sunday Times, Business Section, October 10

Asness, C., Krail, R., and Liew, J. (2001). "Do Hedge Funds Hedge?" The Journal of Portfolio Management 28, 6-19.

Atkins, T. and Hays, S. (2004). "Worries Rise About Indebted Funds of Hedge Funds.” Reuters, October 15.

Bares, P., Gibson, R., and Gyger, S. (2003). "Style Consistency and Survival Probability in the Hedge Funds Industry." Working Paper, University of Zurich.

Baquero, G., Horst, J., and Verbeek, M. (2002). "Survival, Look-Ahead Bias and the Performance of Hedge Funds." Working Paper, Erasmus University, Rotterdam.

Bookstaber, R. (1999). "A Framework for Understanding Market Crisis." In: Risk Management: Principles and Practices. Charlottesville, VA: Association for Investment Management and Research.

Bookstaber, R. (2000). "Understanding and Monitoring the Liquidity Crisis Cycle." Financial Analysts Journal, 17-22.

Boudoukh, J., Richardson, M., Subrahmanyam, M., and Whitelaw, R. (2002). "Stale Prices and Strategies for Trading Mutual Funds." Financial Analysts Journal $58,53-71$

Boyson, N. (2002). "How Are Hedge Fund Manager Characteristics Related to Performance, Volatility and Survival." Working Paper, Ohio State University.

Brooks, C. and Kat, H. (2002). “The Statistical Properties of Hedge Fund Index Returns and Their Implications for Investors." Journal of Alternative Investments 5(2), 25-44.

Brown, S. and Goetzmann, W. (2003). "Hedge Funds With Style.” Journal of Portfolio Management 29, 101-112.

Brown, S., Goetzmann, W., Ibbotson, R., and Ross, S. (1992). "Survivorship Bias in Performance Studies." Review of Financial Studies 5, 553-580. 
Brown, S., Goetzmann, W., and Ibbotson, R. (1999). "Offshore Hedge Funds: Survival and Performance 1989-1995.” Journal of Business 72, 91-118.

Brown, S., Goetzmann, W., and Liang, B. (2002). "Fees on Fees in Funds of Funds." Yale ICF Work Paper No. 02-33.

Brown, S., Goetzmann, W., and Park, J. (2000). "Hedge Funds and the Asian Currency Crisis." Journal of Portfolio Management 26, 95-101.

Brown, S., Goetzmann, W., and Park, J. (2001a). "Conditions for Survival: Changing Risk and the Performance of Hedge Fund Managers and CTAs." Yale School of Management Working Paper No. F-59.

Brown, S., Goetzmann, W., and Park, J. (2001b). "Careers and Survival: Competition and Risks in the Hedge Fund and CTA Industry.” Journal of Finance 56, 1869-1886.

Carpenter, J. and Lynch, A. (1999). "Survivorship Bias and Attrition Effects in Measures of Performance Persistence.” Journal of Financial Economics 54, 337-374.

Chan, N., Getmansky, M., Haas, S., and Lo, A. (2004). "Systemic Risk and Hedge Funds." In: M. Carey and R. Stulz (eds.), The Risks of Financial Institutions and the Financial Sector. Chicago, IL: University of Chicago Press (in press). Chandar, N. and Bricker, R. (2002). "Incentives, Discretion, and Asset Valuation in Closed-End Mutual Funds." Journal of Accounting Research 40, 1037-1070.

Edwards, F. and Caglayan, M. (2001). "Hedge Fund and Commodity Fund Investments in Bull and Bear Markets." The Journal of Portfolio Management 27, 97-108.

Farmer, D. (2002). "Market Force, Ecology and Evolution." Industrial and Corporate Change 11, 895-953.

Farmer, D. and Lo, A. (1999). "Frontiers of Finance: Evolution and Efficient Markets." Proceedings of the National Academy of Sciences 96, 9991-9992.

Feffer, S. and Kundro, C. (2003). "Understanding and Mitigating Operational Risk in Hedge Fund Investments.” Working Paper, The Capital Markets Company Ltd.

Fung, W. and Hsieh, D. (1997a). "Empirical Characteristics of Dynamic Trading Strategies: The Case of Hedge Funds." Review of Financial Studies 10, 275-302.

Fung, W. and Hsieh, D. (1997b). "Investment Style and Survivorship Bias in the Returns of CTAs: The Information Content of Track Records." Journal of Portfolio Management 24, 30-41.

Fung, W. and Hsieh, D. (1999). "A Primer on Hedge Funds.” Journal of Empirical Finance 6, 309-31.

Fung, W. and Hsieh, D. (2000). "Performance Characteristics of Hedge Funds and Commodity Funds: Natural versus Spurious Biases." Journal of Financial and Quantitative Analysis 35, 291-307.
Fung, W. and Hsieh, D. (2001). "The Risk in Hedge Fund Strategies: Theory and Evidence from Trend Followers." Review of Financial Studies 14, 313-341.

Fung, W. and Hsieh, D. (2002a). "Asset-Based Style Factors for Hedge Funds." Financial Analysts Journal 58, 16-27.

Fung, W. and Hsieh, D. (2002b). "Benchmarks of Hedge Fund Performance: Information Content and Measurement Biases." Journal of Alternative Investments 58, 22-34.

Getmansky, M. (2004). "The Life Cycle of Hedge Funds: Fund Flows, Size and Performance.” Unpublished Working Paper, MIT Laboratory for Financial Engineering.

Getmansky, M. and Lo, A. (2003). "A System Dynamics Model of the Hedge Fund Industry." Unpublished Working Paper, MIT Laboratory for Financial Engineering.

Getmansky, M., Lo, A., and Makarov, I. (2004). "An Econometric Analysis of Serial Correlation and Illiquidity in Hedge-Fund Returns." Journal of Financial Economics (in press).

Goetzmann, W., Ingersoll, J., and Ross, S. (2003). "High Water Marks and Hedge Fund Management Contracts." Journal of Finance 58, 1685-1718.

Gregoriou, G. (2002). "Hedge Fund Survival Lifetimes." Journal of Asset Management 3, 237-252.

Greenspan, A. (1998). "Statement before the Committee on Banking and Financial Services, U.S. House of Representatives." Federal Reserve Bulletin 84, 1046-1050.

Hendricks, D., Patel, J., and Zeckhauser, R. (1997). “The J-Shape of Performance Persistence Given Survivorship Bias." Review of Economics and Statistics 79, 161-170.

Horst, J., Nijman, T., and Verbeek, M. (2001). "Eliminating Look-Ahead Bias in Evaluating Persistence in Mutual Fund Performance." Journal of Empirical Finance 8, 345-373.

Howell, M.J. (2001). "Fund Age and Performance." Journal of Alternative Investments 4(2), 57-60.

Ibbotson Associates (2004). Stocks, Bonds, Bills, and Inflation 2004 Yearbook. Chicago, IL: Ibbotson Associates.

Ineichen, A. (2001). "The Myth of Hedge Funds: Are Hedge Funds The Fireflies Ahead of the Storm?” Journal of Global Financial Markets 2(4), 34-46.

Jen, P., Heasman, C., and Boyatt, K. (2001). "Alternative Asset Strategies: Early Performance in Hedge Fund Managers.” Internal Document, Lazard Asset Management, London (http://www.aima.org).

Kao, D. (2000). "Estimating and Pricing Credit Risk: An Overview." Financial Analysts Journal 56, 50-66.

Kao, D. (2002). "Battle for Alphas: Hedge Funds versus LongOnly Portfolios.” Financial Analysts Journal 58, 16-36.

Kramer, D. (2001). "Hedge Fund Disasters: Avoiding the Next Catastrophe." Alternative Investment Quarterly 1. 
Liang, B. (1999). "On the Performance of Hedge Funds." Financial Analysts Journal 55, 72-85.

Liang, B. (2000). "Hedge Funds: The Living and the Dead." Journal of Financial and Quantitative Analysis 35, 309-326.

Liang, B. (2001). "Hedge Fund Performance: 1990-1999." Financial Analysts Journal 57, 11-18.

Liang, B. (2003). "The Accuracy of Hedge Fund Returns." Journal of Portfolio Management 29, 111-122.

Lo, A. (1999). "The Three P's of Total Risk Management." Financial Analysts Journal 55, 87-129.

Lo, A. (2001). "Risk Management for Hedge Funds: Introduction and Overview." Financial Analysts Journal 57, 16-33.

Lo, A. (2002). "The Statistics of Sharpe Ratios." Financial Analysts Journal 58, 36-50.

Lo, A. (2004). "The Adaptive Markets Hypothesis: Market Efficiency from an Evolutionary Perspective." Journal of Portfolio Management 30, 15-29.

Lo, A., Mamaysky, H., and Wang, J. (2004). "Asset Prices and Trading Volume Under Fixed Transactions Costs.” Journal of Political Economy 112, 1054-1090.

Lochoff, R. (2002). "Hedge Funds and Hope.” The Journal of Portfolio Management 28, 92-99.

MacKenzie, D. (2003). "Long-Term Capital Management and the Sociology of Arbitrage." Economy and Society 32, $349-380$
McDonough, W. (1998). "Statement before the Committe on Banking and Financial Services, U.S. House of Representatives.” Federal Reserve Bulletin 84, 1050-1054.

Metzger, L. and The IAFE Investor Risk Committee (2004). "Valuation Concepts for Investment Companies and Financial Institutions and Their Stakeholders." Investor Risk Committee White Paper, International Association of Financial Engineers.

Pérold, A. (1999). Long-Term Capital Management, L.P. (A-D) Harvard Case Study. Boston, MA: Harvard Business School Press.

President's Working Group on Financial Markets (1999). Hedge Funds, Leverage, and the Lessons of Long-Term Capital Management.

Schneeweis, T. and Spurgin, R. (1996). "Survivor Bias in Commodity Trading Advisor Performance." Journal of Futures Markets 16, 757-772.

Watts, D. and Strogatz, S. (1998). "Collective Dynamics of 'Small-World' Networks.” Nature 393, 440-442.

Watts, D. (1999). Small Worlds: The Dynamics of Networks between Order and Randomness. Princeton, NJ: Princeton University Press.

Keywords: Hedge funds; risk management; liquidity 